OPEN ACCESS

Edited by:

Pinarosa Avato,

University of Bari Aldo Moro, Italy

Reviewed by:

Edson Roberto Silva,

University of São Paulo, Brazil

Miriam Rolon,

Centro para el Desarrollo de la

Investigacion Cientifica, Paraguay

*Correspondence:

Kátia da Silva Calabrese

calabrese@ioc.fiocruz.br

${ }^{\dagger}$ These authors have contributed equally to this work

Specialty section:

This article was submitted to

Ethnopharmacology,

a section of the journal

Frontiers in Pharmacology

Received: 01 May 2021

Accepted: 06 July 2021

Published: 20 July 2021

Citation:

Silva-Silva JV, Moragas-Tellis CJ, Chagas MSS, Souza PVR, Souza CSF, Hardoim DJ, Taniwaki NN, Moreira DL, Dutra Behrens M, Calabrese KS and

Almeida-Souza F (2021)

Antileishmanial Activity of FlavonesRich Fraction From Arrabidaea chica

Verlot (Bignoniaceae).

Front. Pharmacol. 12:703985.

doi: 10.3389/fphar.2021.703985

\section{Antileishmanial Activity of Flavones- Rich Fraction From Arrabidaea chica Verlot (Bignoniaceae)}

\author{
João Victor Silva-Silva ${ }^{1 \dagger}$, Carla Junqueira Moragas-Tellis ${ }^{2 t}$, \\ Maria do Socorro dos Santos Chagas ${ }^{2}$, Paulo Victor Ramos de Souza ${ }^{2,3}$, \\ Celeste da Silva Freitas de Souza ${ }^{1}$, Daiana de Jesus Hardoim ${ }^{1}$, Noemi Nosomi Taniwaki ${ }^{4}$, \\ Davyson de Lima Moreira ${ }^{2}$, Maria Dutra Behrens ${ }^{2 \dagger}$, Kátia da Silva Calabrese ${ }^{1 * t}$ and \\ Fernando Almeida-Souza ${ }^{1,5 t}$
}

${ }^{1}$ Laboratory of Immunomodulation and Protozoology, Oswaldo Cruz Institute, Oswaldo Cruz Foundation, Rio de Janeiro, Brazil, ${ }^{2}$ Laboratory of Natural Products for Public Health, Pharmaceutical Techonology Institute - Farmanguinhos, Oswaldo Cruz Foundation, Rio de Janeiro, Brazil, ${ }^{3}$ Student on Postgraduate Program in Translational Research in Drugs and Medicines, Farmanguinhos, Oswaldo Cruz Foundation, Rio de Janeiro, Brazil, ${ }^{4}$ Electron Microscopy Nucleus, Adolfo Lutz Institute, São Paulo, Brazil, ${ }^{5}$ Postgraduate in Animal Science, State University of Maranhão, São Luís, Brazil

Acknowledging the need of identifying new compounds for the treatment of leishmaniasis, this study aimed to evaluate, from in vitro trials, the activity of flavones from Arrabidaea chica against $L$. amazonensis. The chromatographic profiles of the hydroethanolic extract and a flavone-rich fraction (ACFF) from $A$. chica were determined by high-performance liquid chromatography coupled with a diode-array UV-Vis detector (HPLC-DAD-UV) and electrospray ionization mass spectrometry in tandem (LC-ESI-MS-MS). The flavones luteolin (1) and apigenin (2), isolated from chromatographic techniques and identified by Nuclear Magnetic Resonance of ${ }^{1} \mathrm{H}$ and ${ }^{13} \mathrm{C}$, were also quantified in ACFF, showing $190.7 \mathrm{mg} / \mathrm{g}$ and apigenin $12.4 \mathrm{mg} / \mathrm{g}$, respectively. The other flavones were identified by comparing their spectroscopic data with those of the literature. The in vitro activity was assayed against promastigotes and intramacrophagic amastigote forms of L. amazonensis. Cytotoxicity tests were performed with peritoneal macrophages of BALB/c mice. Nitrite quantification was performed with Griess reagent. Ultrastructural investigations were obtained by transmission electron microscopy. Anti-Leishmania assays indicated that the $\mathrm{IC}_{50}$ values for ACFF, apigenin, and luteolin were obtained at $40.42 \pm 0.10$ and $31.51 \pm 1.13 \mu \mathrm{g} / \mathrm{mL}$ against promastigotes, respectively. ACFF and luteolin have concentration-dependent cytotoxicity. ACFF and luteolin also inhibited the intra-macrophagic parasite ( $\mathrm{IC}_{50} 3.575 \pm 1.13$ and $11.78 \pm 1.24 \mu \mathrm{g} / \mathrm{mL}$, respectively), with a selectivity index of 11.44 for ACFF. Promastigotes exposed to ACFF and luteolin exhibited ultrastructural changes, such as intense cytoplasm vacuolization and mitochondrial swelling. These findings data evidence the antileishmanial action of flavone-rich fractions of $A$. chica against $L$. amazonensis, encouraging further studies.

Keywords: L. amazonensis, flavonoids, Arrabidaea chica, macrophages, nitric oxide, transmission electron microscopy 


\section{INTRODUCTION}

Flavonoids are an important class of secondary metabolites with a low molecular weight polyphenolic structure, widely distributed in the plant kingdom among subgroups that include chalcones, flavones, flavonols, and isoflavones (Panche et al., 2016). This metabolic class has its biological and therapeutic activity experimentally determined (Nijveldt et al., 2001), being able to affect enzymes and various cellular systems, having beneficial effects on the body (Silva et al., 2010). Furthermore, it is largely known that flavonoids have a wide spectrum of antileishmanial activity (Fotie, 2008; Wong et al., 2012; Rocha et al., 2018).

Leishmaniasis is a neglected tropical disease that seriously affects humans and can lead to death if left untreated (Reithinger and Dujardin, 2007). This protozoosis represents a global health challenge, since it has a worldwide distribution, with an estimate of more than one billion people living in endemic areas and at risk of Leishmania infection (World Health Organization, 2020). In addition to these circumstances, the anti-leishmanial drugs currently in use exhibit drug resistance, toxicity, and high cost, which may explain the low adherence to treatment (Sundar et al., 2019). The lack of new therapeutic alternatives to leishmaniasis highlights the need to seek new compounds with leishmanicidal activities. In this context, the use of natural products in traditional medicine has contributed to the identification of candidate compounds for the development of new drugs. Therefore, medicinal plants represent a repository of bioactive compounds potentially useful for the development of new therapeutic alternatives for leishmaniasis (da Silva et al., 2018).

Arrabidaea chica (Humb. \& Bonpl.) B. Verlot, syn. Bignonia chica, belongs to the family Bignoniaceae. It comprises about 120 genera and 860 species (Fischer et al., 2004; Sampaio et al., 2016). A. chica occurs in tropical America, being a very common species in the Amazon region (Takemura et al., 1995; dos Santos et al., 2013) and is popularly known as crajiru or pariri (Behrens et al., 2012). It is traditionally used as a medicinal plant in the Amazon region (Takemura et al., 1995), with the use of tea made from leaves as an anti-inflammatory (Evangelista et al., 2013), to treat skin inflammation and mycoses (Corrêa, 1984), and has astringent properties (Lima de Medeiros et al., 2011). Amazonian Indians use the decoction of leaves to clean wounds and ulcers to aid in healing, in addition to the use to treat fungal infections and herpes (Lorenzi and Matos, 2002), as well as for other skin conditions (Barbosa et al., 2008). Furthermore, the infusion (oral use) is used to heal wounds and cleanse the blood (Bieski et al., 2012). Previous studies have demonstrated its antioxidant (do Amaral et al., 2012; dos Santos et al., 2013), wound healing (Aro et al., 2013; Cortez de Sá et al., 2015), trypanocidal (Barbosa et al., 2008; Miranda et al., 2017) and leishmanicidal activities (Rodrigues et al., 2014; Cortez de Sá et al., 2015; Moragas-Tellis et al., 2020). In the phytochemical screening of extracts of A. chica, the leaves are rich in anthocyanidins, such as carajurin and carajurone (Moragas-Tellis et al., 2020); in addition to some flavones (Paula et al., 2013), such as luteolin and apigenin (do Amaral et al., 2012).
Thus, the present study aimed to evaluate the antileishmanial activity in vitro of the hydroethanolic extract derived from $A$. chica, as well as of its flavone-rich fraction and the isolated flavones, luteolin and apigenin, against promastigotes, and intracellular amastigotes of Leishmania amazonensis.

\section{MATERIALS AND METHODS}

\section{Plant Material}

Leaves of $A$. chica Verlot (Bignoniaceae) (morphotype IV) were cultivated and collected in March 2016 at Fiocruz Atlantic Forest Campus, municipality of Rio de Janeiro, Rio de Janeiro State, Brazil (S22.9406 W43.4046). Plant material was identified by Dr. Marcus Felipe Oliveira da Silva at the Botanical Collection of Medicinal Plants of Farmanguinhos/FIOCRUZ, where a voucher specimen was deposited and registered under the number CBPM666.

\section{Extraction and Isolation}

Arrabidaea chica leaves were dried in a forced circulation oven at a temperature of $45^{\circ} \mathrm{C}$ for 4 days. After drying, the plant material was powered using a knife-mill affording $0.85 \mathrm{~mm}$ particles that were stored in an amber flask. The hydroethanolic extract was prepared by exhaustive maceration of dried and powdered leaves $(1.5 \mathrm{~kg})$ in $70 \%$ ethanol solution $(\mathrm{v} / \mathrm{v})$ with three changes of solvent, once every $48 \mathrm{~h}$ for 7 days at room temperature. After filtration, the solvent was evaporated under reduced pressure to yield $226.19 \mathrm{~g}$ of a red extract (ACCE) corresponding to yielding of $15.07 \%$. The crude hydroethanolic extract $(60 \mathrm{~g})$ was then submitted to liquid-liquid partition with $n$-hexane $(3 \times 200 \mathrm{~mL})$, dichloromethane $(3 \times 200 \mathrm{~mL})$, ethyl acetate $(3 \times 200 \mathrm{~mL})$ and $n$-butanol $(3 \times 200 \mathrm{~mL})$. The final aqueous residue was discarded. Dichloromethane fraction was successively chromatographed by column chromatography on Sephadex LH-20 (Sigma, St Louis, MO, United States), using methanol as eluent to produce a purified flavone-rich fraction determined by thin layer chromatoghapy (TLC) analysis, and named ACFF. Successive chromatographic fractionation steps of ACFF on Sephadex LH20 led to the isolation of two flavonoids ( $\mathrm{F} 1=24 \mathrm{mg} ; \mathrm{F} 2=4 \mathrm{mg}$ ). Isolated compounds and a flavone-rich fraction were analyzed by TLC (silica gel $\mathrm{F}_{254}$, Merck, Darmstadt, Germany) using acetone: chloroform: formic acid (75:16:0.8 v/v/v) as eluent and, subsequently, sprayed with $1 \%$ NP/PEG reagent (diphenylboriloxyethilamine/polyetileneglicol, Sigma, St Louis, MO, United States), as well as ${ }^{1} \mathrm{H}$ and ${ }^{13} \mathrm{C}$ NMR spectrometry. Comparison with literature records allowed the identification of (1) luteolin and (2) apigenin (Ersöz et al., 2002; Özgen et al., 2011; Siraichi et al., 2013; Grabsk et al., 2017).

(1) Luteolin 1H NMR (400 MHz-methanol-d6) d: $6.47(\mathrm{~s}, 1 \mathrm{H}$, $\mathrm{H}-3) ; 6.13$ (d, 1H, H-6, J = 2.0 Hz); 6.35 (d, 1H, H-8, J = 2.0 Hz); 7.35 (d, $\left.1 \mathrm{H}, \mathrm{H}-2^{\prime}, \mathrm{J}=2.2 \mathrm{~Hz}\right) ; 6.88$ (d, $\left.1 \mathrm{H}, \mathrm{H}-5^{\prime}, \mathrm{J}=8.2 \mathrm{~Hz}\right) ; 7.35$ (dd, $\left.1 \mathrm{H}, \mathrm{H}-6^{\prime}, \mathrm{J}=8.2 \mathrm{~Hz}, \mathrm{~J}=2.2 \mathrm{~Hz}\right) .13 \mathrm{C} \mathrm{NMR}(400 \mathrm{MHz}-$ methanol-d6) d: 166.05 (C-2); 103.41(C-3); 183.49 (C-4); 163.05 (C-5); 95.91(C-6); 166.05 (C-7); 101.31 (C-8); 159.72 (C-9); 104.27 (C-10); $123.43\left(\mathrm{C}-1^{\prime}\right) ; 113.89\left(\mathrm{C}-2^{\prime}\right) ; 147.31\left(\mathrm{C}-3^{\prime}\right)$; $151.65\left(\mathrm{C}-4^{\prime}\right) ; 116.86\left(\mathrm{C}-5^{\prime}\right) ; 120.23\left(\mathrm{C}-6^{\prime}\right)$. 
(2) Apigenin 1H NMR (400 MHz, Methanol-d6) d: 6.55 (s, 1H, $\mathrm{H}-3) ; 6.16$ (d, 1H, H-6, J = 2.0 Hz); 6.39 (d, 1H, H-8, J = $2.0 \mathrm{~Hz}$ ); $7.35\left(\mathrm{~d}, 1 \mathrm{H}, \mathrm{H}-2^{\prime}\right.$ and $\left.\mathrm{H}-6^{\prime}, \mathrm{J}=2.2 \mathrm{~Hz}\right) ; 6.88\left(\mathrm{~d}, 1 \mathrm{H}, \mathrm{H}-3^{\prime}\right.$ and $\mathrm{H}-5^{\prime}$, $\mathrm{J}=8.2 \mathrm{~Hz}$ ); 13C NMR (400 MHz-Methanol-d6) d: 170.32 (C-2); 103.60 (C-3); 183.69 (C-4); 163.15 (C-5); 100.93 (C-6); 166.08 (C-7); 95.65 (C-8); 163.93 (C-9); 104.65 (C-10); $123.25\left(\mathrm{C}-1^{\prime}\right) ; 129.42\left(\mathrm{C}-2^{\prime}\right.$ and $\left.\mathrm{C}-6^{\prime}\right) ; 117.14\left(\mathrm{C}-3^{\prime}\right.$ and $\left.\mathrm{C}-5^{\prime}\right) ; 159.65\left(\mathrm{C}-4^{\prime}\right)$.

\section{High-Performance Liquid Chromatograph Coupled With a Diode-array UV-Vis Detector}

Chromatographic analyses were performed on HPLC-DAD-UV using a Shimadzu Nexera XR ${ }^{\circledR}$ liquid chromatographer coupled to a Shimadzu UV detector with diode array SPDM20A, equipped with a CBM20A controller, DGU20A degasser, LC20AD binary pump, CTO20A oven, and SILA20A autoinjector. A Shimadzu LabSolutions Software Version 5.3 (Shimadzu, Kyoto, Japan) was used to analyze chromatograms. Combinations of acidified ultrapure water $(\mathrm{pH} 3.0$, with anhydrous acetic acid, Merck, Darmstadt, Germany) (A) and acetonitrile (HPLC grade, Tedia, Rio de Janeiro, Brazil) (B) were used as the mobile phase (initially $5 \%$ A rising to $95 \%$ in $80 \mathrm{~min}$ ). HPLC column was silica-based C18 $(250 \mathrm{~mm} \times 4.6 \mathrm{~mm}$ i.d. $\times$ $5 \mu \mathrm{m}$ particle size, ODS Hypersil, Thermo, Waltham, MA, United States). The oven was set at $50^{\circ} \mathrm{C}$ and the injection volume was $10 \mu \mathrm{L}$ for all analyses.

\section{Preparation of $A$. chica Hydroethanolic Extract (ACCE) and Flavone-Rich Fraction (ACFF) Samples}

A total of $1,000 \mu \mathrm{L}$ of acetonitrile: methanol (both HPLC grade, Tedia, Rio de Janeiro, Brazil) mixture (75:25; v/v) was added to $5 \mathrm{mg}$ of ACCE and ACFF, previously weighed in a $4 \mathrm{~mL}$ vial. The vial was sealed and the sample was sonicated for $10 \mathrm{~min}$ with occasional swirling. Posteriorly, the sample was vortexed to mix thoroughly, followed by filtering through a $0.45 \mu \mathrm{m}$ PTFE filter (Merck Millipore, Darmstadt, Germany) before further analyses into an HPLC vial.

\section{Preparation of Standard Solutions and Quantification of Luteolin and Apigenin}

Stock solutions of analytical standards luteolin and apigenin (Lot. 2,578 and 2,968, Phytolab, Vestenbergsgreuth, Germany) were prepared at $1,000 \mathrm{mg} / \mathrm{mL}$ in $\mathrm{MeOH}$ (Tedia, Rio de Janeiro, Brazil) in volumetric flasks. Six concentration of work solutions $(1 ; 4 ; 8$; $12 ; 16$, and $20 \mu \mathrm{g} / \mathrm{mL}$ ) were done on the day for calibration curves of each compound. The solutions were filtered in a $0.45 \mu \mathrm{m}$ PTFE filter (Merck Millipore, Darmstadt, Germany) before analyses by HPLC-DAD-UV. Injections of $20 \mu \mathrm{L}$ were performed in triplicate to obtain the calibration curves from the areas corresponding to the peaks of luteolin and apigenin. The analytical curve (1-20 $\mu \mathrm{g} /$ $\mathrm{mL}$ ) of the standards was plotted based on the UV-Vis signal at $254 \mathrm{~nm}$ : luteolin content $(\mu \mathrm{g} / \mathrm{mL})=(\mathrm{Abs}(\mathrm{mAu})+21,030) / 83,557$; $\mathrm{R} 2=0.9995$ and apigenin content $(\mu \mathrm{g} / \mathrm{mL})=(\mathrm{Abs}(\mathrm{mAu})+27,059) /$ 77,$296 ; \mathrm{R} 2=0.996$. Flavones amounts were calculated in $\mathrm{mg} / \mathrm{g}$ of dry extract. The following dilution factors were used for luteolin and apigenin quantitative analysis: 147.06 and 11.47, respectively.

\section{Liquid Chromatography Coupled to Electrospray ionization Mass spectrometry in Tandem Analysis}

Liquid chromatography coupled to electrospray ionization mass spectrometry in tandem (LC-ESI-MS-MS) was performed with an LC Shimadzu Nexera Ultra-Fast Liquid Chromatography (UFLC) coupled to an ion trap Bruker amaZon MS. Analyses were performed at ambient temperature in a silica-based C18 column $(150 \mathrm{~mm} \times 4.6 \mathrm{~mm}$ i.d. x $2.6 \mu \mathrm{m}$ particle size, Kinetex C18 gravity column, Phenomenex, CA, United States). The mobile phase consisted of ultrapure water obtained from the Milli-Q Millipore purification system, acidified at $\mathrm{pH} 3.0$ with anhydrous acetic acid (Merck, Darmstadt, Germany) (A) and acetonitrile (HPLC grade, Tedia, Rio de Janeiro, Brazil) (B). The gradient of B was as follows: in 54.86 min from 5 to $95 \%$; from 54.86 to $55.54 \mathrm{~min}$ returns to $5 \% \mathrm{~B}$, remaining like this until $62.0 \mathrm{~min}$ to column re-equilibration. The flow rate was set at $0.5 \mathrm{~mL} / \mathrm{min}$ and the injection volume was $1 \mu \mathrm{L}$. ESI-MS/MS were recorded in a Bruker Ion trap amazon SL mass spectrometer in the positive ionization mode (ESI+). The operating conditions were $1 \mu \mathrm{L} / \mathrm{min}$ infusion, $3.0-4.0 \mathrm{kV}$ capillary voltage, $100^{\circ} \mathrm{C}$ temperature source, and cone voltage of 20-40 V. Mass spectra were recorded and interpreted by Bruker Compass Data Analysis 4.2 (Bruker Daltonics, Boston, MA, United States).

\section{Animals and Ethical Statements}

All procedures performed with 4-6-weeks old female BALB/c mice were in accordance with the National Council for Control of Animal Experimentation (CONCEA). These animals were obtained from the Institute of Science and Technology in Biomodels of Oswaldo Cruz Institute and the experiments were approved by the local Ethics Committee on Animal Care and Utilization (CEUA-IOC L53/2016).

\section{Parasites}

Leishmania amazonensis H21 (MHOM/BR/76/MA-76) was maintained in the laboratory by successive passages in BALB/c mice. Parasites were isolated from a non-ulcerated nodular lesion in the footpad and amastigote viability was checked by light microscopy. $10^{6}$ amastigote forms were transferred to the NNN medium (Novy-MacNeal-Nicolle) and maintained for seven days to differentiate into promastigote forms. Then, these forms were cultured at $26^{\circ} \mathrm{C}$ in Schneider's Insect medium (Sigma, St Louis, MO, United States), supplemented with $10 \%$ fetal bovine serum (Gibco, Gaithersburg, MD, United States), $100 \mathrm{IU} / \mathrm{mL}$ of penicillin, and $100 \mu \mathrm{g} / \mathrm{mL}$ of streptomycin in a maximum of ten in vitro passages (Almeida-Souza et al., 2016).

\section{Peritoneal Macrophage Obtaining and Cell Culture}

The animals were previously inoculated intraperitoneally, with $3.0 \mathrm{~mL}$ of $3 \%$ sodium thioglycolate. After $72 \mathrm{~h}$ of stimulation, the 
animals were euthanized with $10 \%$ ketamine and $2 \%$ xylazine according to the weight of each animal and, after death, the abdomen skin was retracted for peritoneum exposure. $10.0 \mathrm{~mL}$ of sterile $\mathrm{pH} 7.2$ phosphate-buffered saline was inoculated and a light manual massage was performed. The cells were harvested from the peritoneum with the same syringe and dispensed in a sterile conical tube to prepare the cell suspension. The cells were centrifuged at 2,000 rpm for $5 \mathrm{~min}$ and suspended in RPMI 1640 medium supplemented with $10 \%$ fetal bovine serum (FBS), penicillin $(100 \mathrm{U} / \mathrm{mL})$ and $(100 \mu \mathrm{g} / \mathrm{mL})$ streptomycin, at $37^{\circ} \mathrm{C}$ and $5 \% \mathrm{CO}_{2}$ and grown overnight (Almeida-Souza et al., 2018).

\section{Activity Against $L$. amazonensis Promastigote Forms}

To evaluate the anti-promastigote effects of the ACCE, ACFF, and isolated flavonoids from A. chica on the promastigote forms of L. amazonensis, viable promastigotes were counted in a Neubauer chamber according to the method described by Rottini et al. (2019). In brief, $50 \mu \mathrm{L}$ of the promastigotes $(2 \times$ $10^{6}$ cells $/ \mathrm{mL}$ ) harvested from the logarithmic growth phase were added to 96-well flat-bottomed microtiter plates. Then, $50 \mu \mathrm{L}$ of the ACCE $(62.5-1,000 \mu \mathrm{g} / \mathrm{mL})$, ACFF $(12.5-200 \mu \mathrm{g} / \mathrm{mL})$ or isolated flavonoids $(3.125-100 \mu \mathrm{g} / \mathrm{mL})$ were added to each well and incubated at $26 \pm 1{ }^{\circ} \mathrm{C}$ for $72 \mathrm{~h}$. Wells with parasites and DMSO $1 \%$ only were used as untreated control and amphotericin B $(0.03125-1.0 \mu \mathrm{g} / \mathrm{mL})$ was used as a reference drug. After the incubation, viable promastigotes were counted in a Neubauer chamber. The experiments were conducted in triplicate. Percentage of growth inhibition was calculated from the count of viable parasites relative to the untreated control, and $50 \%$ inhibitory concentration $\left(\mathrm{IC}_{50}\right)$ values were determined.

\section{Cytotoxicity Assay}

Peritoneal macrophages collected as previously described (Peritoneal Macrophage Obtaining and Cell Culture) were seeded at $5 \times 10^{5}$ cells per milliliter in a 96-well plate and allowed to adhere overnight at $37^{\circ} \mathrm{C}$ and $5 \% \quad \mathrm{CO}_{2}$. Subsequently, the cells were treated with different concentrations of the ACCE, ACFF (both with concentrations of $7.81-1,000 \mu \mathrm{g} / \mathrm{mL})$, flavonoids $(1.95-500 \mu \mathrm{g} / \mathrm{mL})$ or amphotericin B $(0.19-25 \mu \mathrm{g} / \mathrm{mL})$, in a final volume of $100 \mu \mathrm{L} /$ well, incubated for $72 \mathrm{~h}$ at the same conditions. Wells without cells were used as blank and wells with cells and 1\% DMSO were used as controls. The cytotoxicity was determined with the MTT (Sigma, St Louis, MO, United States) assay. Half-maximal cytotoxic concentration $\left(\mathrm{CC}_{50}\right)$ was calculated according to Oliveira et al. (2018).

\section{Activity Against $L$. amazonensis Intracellular Amastigotes and Selectivity Index}

Peritoneal macrophages of BALB/c mice were cultured in 24-well plates $\left(5 \times 10^{5}\right.$ cells/well $)$, containing round coverslips and incubated at $37^{\circ} \mathrm{C}$ in $5 \% \mathrm{CO}_{2}$ overnight. The cells were then infected with promastigote forms of L. amazonensis, in the parasite/cell ratio of $10: 1$, for $6 \mathrm{~h}$ followed by washing with PBS to remove free parasites. Infected cells were treated with different concentrations of ACFF $(0.15-2.5 \mu \mathrm{g} / \mathrm{mL})$ or luteolin $(1.56-25 \mu \mathrm{g} / \mathrm{mL})$, and the plates were incubated in similar conditions for $24 \mathrm{~h}$. The macrophages containing amastigotes without compounds treatment and those treated with amphotericin B $(2.5-0.15 \mu \mathrm{g} / \mathrm{mL})$ were considered the negative and positive controls, respectively. Finally, the coverslips of the infected and treated cells were fixed in Bouin's solution, stained by Giemsa and observed under a light microscope. The activity anti-intramacrophage amastigotes of the compounds was evaluated by counting the number of amastigotes in each macrophage by examining 200 macrophages in comparison with the untreated control. The percentage of infected cells was obtained from the number of infected cells divided by two. The mean number of amastigotes per cell was obtained from the number of intracellular amastigotes in 200 cells divided by the number of infected cells (Almeida-Souza et al., 2020). The percentage inhibition was calculated and $\mathrm{IC}_{50}$ was obtained by GraphPad Prism ${ }^{\circledast}$ version 7 (GraphPad Software Inc., San Diego, CA, United States). Selectivity index (SI), which was calculated using the equation of $\mathrm{CC}_{50}$ for murine macrophage/ $\mathrm{IC}_{50}$ for the intracellular amastigote forms of L. amazonensis, was used to compare the toxicity and activity of the compounds.

\section{Nitrite Quantification}

Nitric oxide (NO) release was indirectly measured in the supernatants of macrophage culture $\left(5 \times 10^{6}\right.$ cells $\left./ \mathrm{mL}\right)$ by the Griess reaction for nitrite according to the method described by Almeida-Souza et al. (2016). About $50 \mu \mathrm{L}$ of the supernatants were collected $48 \mathrm{~h}$ after treatment with ACFF $(2.5 \mu \mathrm{g} / \mathrm{mL})$ or luteolin $(25 \mu \mathrm{g} / \mathrm{mL})$ and/or stimulation twith L. amazonensis $(3 \times$ $10^{7}$ parasites $/ \mathrm{mL}$ ), and added in 96 -well plates. Then, were added to supernatants $50 \mu \mathrm{L}$ of Griess reagent $(25 \mu \mathrm{L}$ of sulfanilamide $1 \%$ in $2.5 \% \mathrm{H}_{3} \mathrm{PO}_{4}$ solution and $25 \mu \mathrm{L}$ of $\mathrm{N}$-(1-naphthyl ethylenediamine $0.1 \%$ solution). After $10 \mathrm{~min}$, the plates were read at $570 \mathrm{~nm}$ on the spectrophotometer and the nitrite values were obtained from the standard sodium nitrite curve $(1.5-100 \mu \mathrm{M})$.

\section{Transmission Electron Microscopy}

Promastigote forms of $L$. amazonensis were treated with $\mathrm{IC}_{50}$ for ACFF or luteolin, for $24 \mathrm{~h}$. Non-treated parasites were used as a negative control. After $24 \mathrm{~h}$-incubation at $26^{\circ} \mathrm{C}$ promastigotes were collected by centrifugation at $5,000 \mathrm{rpm}$ for $5 \mathrm{~min}$. The parasites were fixed with $2.5 \%$ glutaraldehyde (Sigma, St Louis, $\mathrm{MO}$, United States) in $0.1 \mathrm{M}$ sodium cacodylate buffer, $\mathrm{pH} 7.2$, overnight. Then, parasites were washed three times with $0.1 \mathrm{M}$ sodium cacodylate buffer and post-fixed in a solution containing $1 \%$ osmium tetroxide, $0.8 \%$ potassium ferrocyanide, and $5 \mathrm{mM}$ calcium chloride, washed in $0.1 \mathrm{M}$ sodium cacodylate buffer, dehydrated in graded acetone, and embedded in EPON 812 resin (Sigma, St Louis, MO, United States). Ultrathin sections were obtained from $100 \mathrm{~nm}$ cuts in Sorvall MT 2-B (Porter Blum) ultramicrotome (Sorvall, Newtown, CT, United States) stained with $5 \%$ uranyl acetate aqueous solution and lead citrate $(1.33 \%$ lead nitrate and $1.76 \%$ sodium citrate), and examined in a 


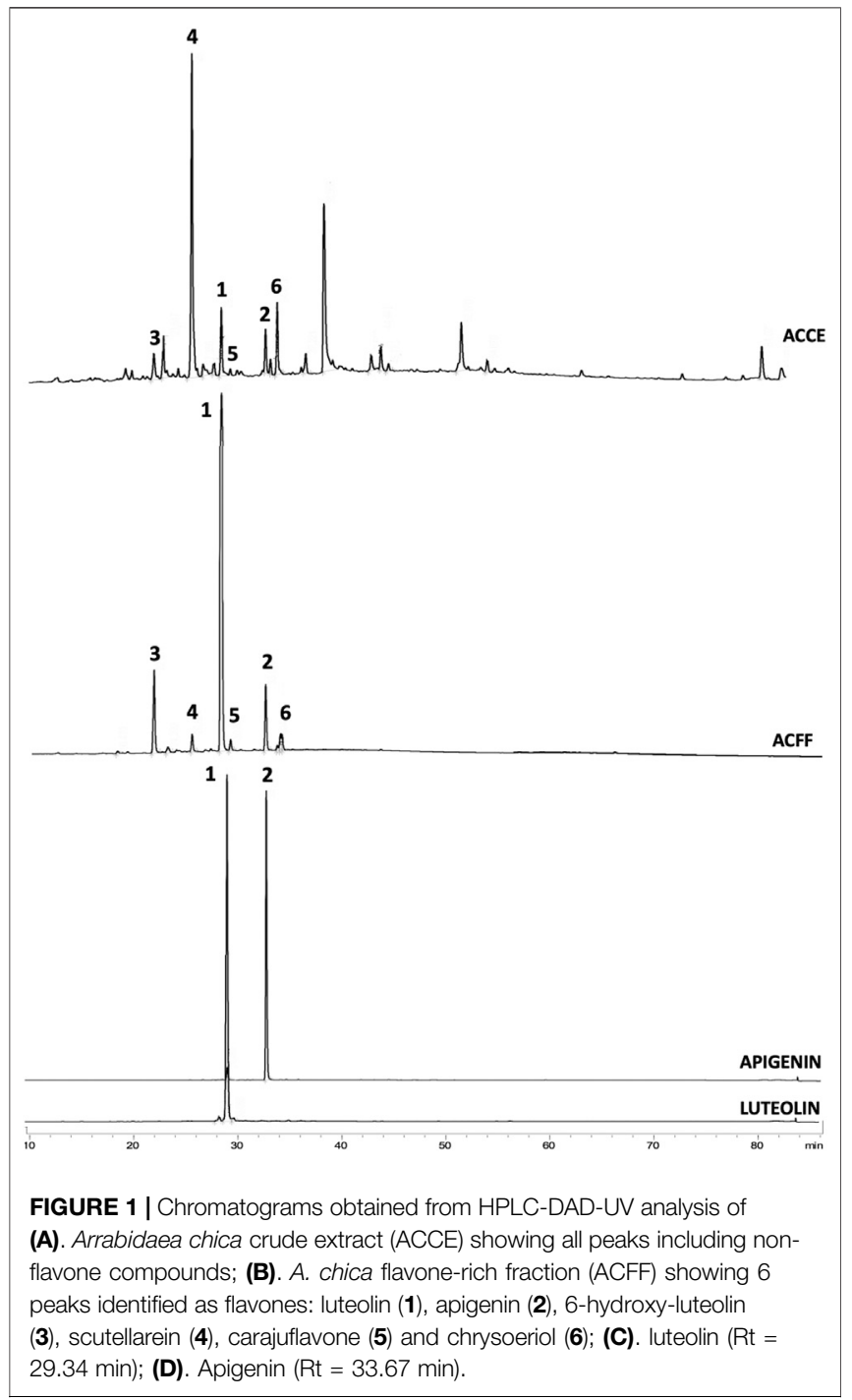

transmission electron microscope JEM-1011 (JEOL, Tokyo, Japan) operating at $80 \mathrm{kV}$ (Mondêgo-Oliveira et al., 2021).

\section{Statistical Analysis}

The numerical results were expressed as mean \pm standard deviation and the statistical analyses were conducted through the statistical software GraphPad Prism ${ }^{\circledR}$ version 7. The differences were considered significant when $p<0.05$ by one-way analysis of variance (ANOVA) and MannWhitney test.

\section{RESULTS}

\section{High-Performance Liquid Chromatograph Coupled With a Diode-Array UV-Vis Detector and Liquid Chromatography Coupled to Electrospray Ionization Mass Spectrometry in Tandem}

The comparison between the profiles of ACCF and ACFF of $A$. chica (Figure 1) by HPLC-DAD-UV showed that the chromatographic fractionation steps were useful both to obtain a fraction rich in flavones, and isolating two of them, luteolin (1) and apigenin (2), which had already been reported in the literature, and had their structures confirmed by ${ }^{1} \mathrm{H}$ and ${ }^{13} \mathrm{C}$ NMR (Özgen et al., 2011; Siraichi et al., 2013).

LC-ESI-MS-MS analysis in positive mode of the flavone-rich fraction (ACFF) also resulted in a chromatogram with six peaks (Figure 2). Mass spectrometry in tandem (MS-MS) and pseudomolecular ions $[\mathrm{M}+\mathrm{H}]^{+}$were useful to identify and confirm the structures of the six flavones in flavone-rich fraction.

The results of HPLC-DAD-UV and LC-ESI-MS-MS allowed the identification of the six component flavones of the rich fraction in flavonoids of A. chica, as shown in Table 1.

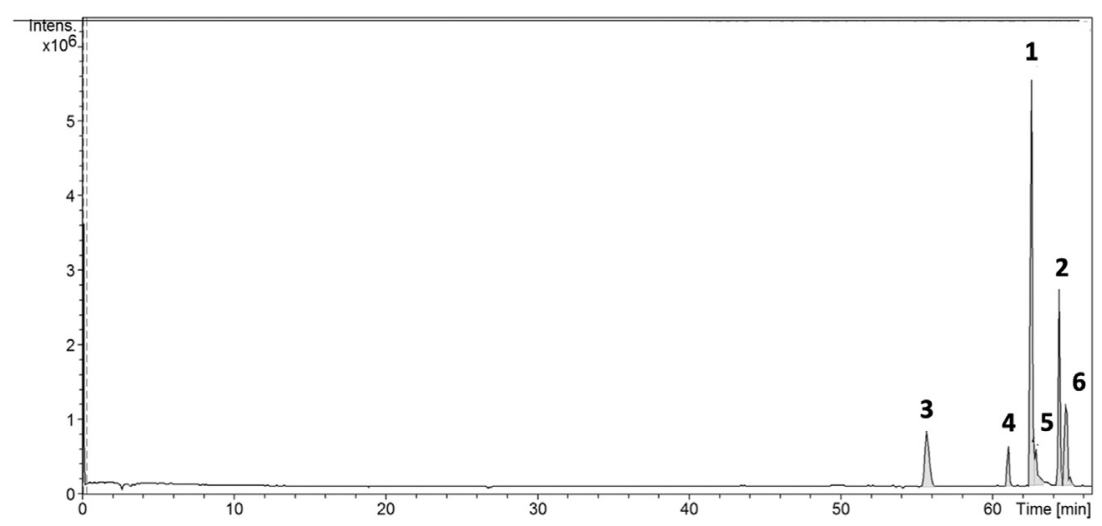

FIGURE 2 | Chromatogram obtained from LC-ESI-MS-MS analysis of the flavone-rich fraction of Arrabidaea chica Verlot, also presenting 6 peaks of flavones. Luteolin (1), apigenin (2), 6-hydroxy-luteolin (3), scutellarein (4), carajuflavone (5), and chrysoeriol (6). 
TABLE 1 | LC-ESI-MS-MS and HPLC-DAD-UV data of flavone-rich fraction obtained from Arrabidaea chica Verlot.

\begin{tabular}{|c|c|c|c|c|c|c|}
\hline \multirow[t]{2}{*}{ Peak } & \multicolumn{2}{|c|}{ LC-ESI-MS-MS } & \multirow[t]{2}{*}{ MS-MS } & \multicolumn{2}{|c|}{ HPLC-DAD-UV } & \multirow[t]{2}{*}{ Identification } \\
\hline & Rt (min) & {$[\mathbf{M}+\mathbf{H}]$} & & Rt (min) & $\begin{array}{l}\text { UV data } \\
\text { (nm) }\end{array}$ & \\
\hline 3 & 55.7 & 303.0451 & $303,257,169$ & 22.9 & 346,282 & 6-OH-luteolin \\
\hline 4 & 61.0 & 287.0496 & 287,169 & 26.6 & 338,283 & Scutellarein \\
\hline 1 & 62.6 & 287.0493 & $287,241,153$ & 29.8 & 348,256 & Luteolin \\
\hline 5 & 62.9 & 317.0594 & $317,302,168$ & 30.3 & 346,271 & Carajuflavone \\
\hline 2 & 64.4 & 271.0548 & 271,153 & 33.6 & 339,267 & Apigenin \\
\hline 6 & 64.8 & 301.0464 & $301,286,258,153$ & 35.0 & 343,267 & Chrysoeriol \\
\hline
\end{tabular}

LC-ESI-MS-MS: Liquid chromatography coupled to electrospray ionization mass spectrometry. HPLC-DAD-UV: High-performance liquid chromatography coupled to a diode-array detector. $[M+H]$ : pseudomolecular ions. MS-MS: Mass spectrometry. Rt: retention time.

TABLE 2 | Quantification of luteolin and apigenin ( $\mathrm{mg} / \mathrm{g}$ dry extract) content in the flavone-rich fraction of Arrabidea chica Verlot.

\begin{tabular}{lccc}
\hline Flavone & Area (mAU) & Concentration $\mathbf{( m g / g )}$ & RSD (\%) \\
\hline Luteolin (1) & $1,062,597 \pm 1,326.92$ & $190.717 \pm 0.015$ & 0.12 \\
Apigenin (2) & $811051.3 \pm 4,500.54$ & $12.4367 \pm 0.058$ & 0.54
\end{tabular}

Values are expressed as the mean $\pm S D(n=3$, see experimental). $R S D$ : relative standard deviation; Content $(\mathrm{mg} / \mathrm{g})$ for luteolin $=($ area $+21,030) / 83,557^{\star} 147.06$ (dilution factor); content $(\mathrm{mg} / \mathrm{g})$ for apigenin $=($ area $+27,059) / 77,296^{*} 11.47$ (dilution factor).

\section{Quantification of Luteolin and Apigenin in the Flavone-Rich Fraction}

Chromatographic investigation of the analytes was realized by comparing the retention time (Rt) and UV spectra of the corresponding peaks in the flavone-rich fraction with authentic standards apigenin and luteolin. Flavones quantification was carried out through calibration curves obtained by triplicate injections. Calibration curves showed to be linear in the ranges of $1-20 \mu \mathrm{g} / \mathrm{mL}$ for luteolin and apigenin. Besides that, good regression coefficients $\left(r^{2}\right)$ for linear regression equations of both standards were obtained: 0.9995 for luteolin and 0.9960 for apigenin. Luteolin and apigenin contents were calculated using the equations Absorbance $(\mathrm{mAu})=83,557$ (concentration)-21,030 and Absorbance $(\mathrm{mAu})=77,296$ (concentration) -27,059, respectively. The content of luteolin and apigenin (Table 2) were obtained in $\mathrm{mg} / \mathrm{g}$ of dry weight, after correction by dilution factor, when necessary.

\section{Leishmanicidal Activity of Flavonoids Obtained From A. chica}

Growth inhibitory activity by the selected compounds was performed on L. amazonensis promastigotes forms. In the test, all evaluated compounds from $A$. chica showed antipromastigote effects (Table 3). The results also revealed that ACFF caused leishmanicidal effects on the promastigotes of L. amazonensis 3fold more potent in comparison with the ACCE. Moreover, the $\mathrm{IC}_{50}$ value for the flavonoids apigenin and luteolin against promastigotes of L. amazonensis were similar to their original fraction, ACFF.

Evaluation of cytotoxicity showed that ACFF was the less cytotoxic compound, followed by ACCE, and the flavonoids apigenin and luteolin were more cytotoxic having $\mathrm{CC}_{50}$ similar to amphotericin B (Table 3). The cytotoxicity against peritoneal macrophage and $L$. amazonensis were compared using the selectivity index (SI) (Table 3).

From the results described in Table 3, ACFF and luteolin were selected for evaluation against intra-macrophage forms. We found that luteolin inhibited the intracellular amastigote number. However, results demonstrated that the ACFF was 3.3-fold more effective for the amastigotes than luteolin. Therefore, considering this increased activity against intracellular amastigote, we observed a promising selectivity for the fraction rich in flavonoids $(\mathrm{SI} / 24 \mathrm{~h}>10.0)$. Amphotericin B showed leishmanicidal activity and cytotoxicity as expected.

TABLE 3 | Cytotoxicity and antileishmanial activity of extracts and isolated flavonoids from Arrabidaea chica.

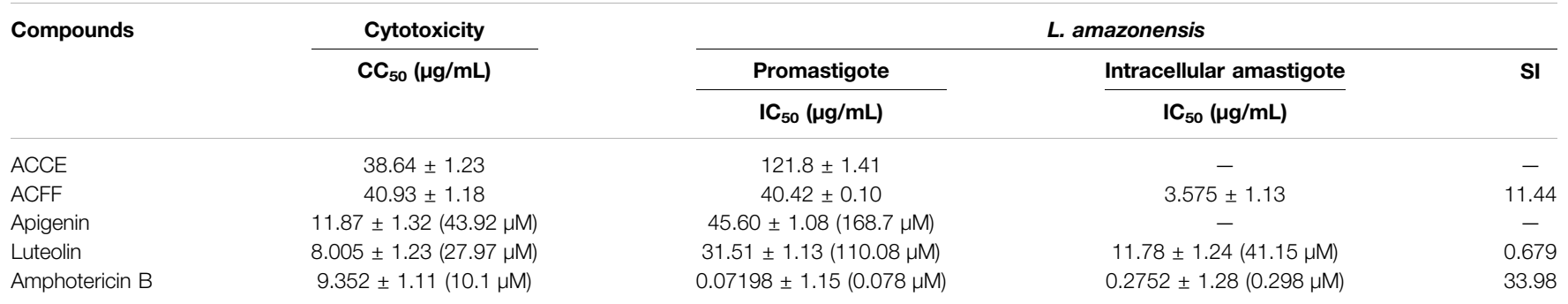

ACCE: A. chica crude extract; ACFF: fraction rich in flavonoids of A. chica. Data represent mean $\pm S D$ of at least two experiments realized in triplicate. $C C_{50}$ : half-maximal cytotoxic concentration for $50 \%$ of cells; $I C_{50}$ : $50 \%$ inhibitory concentration of parasites; SI: selectivity index, $S I=C C_{50} / I_{50}$ intracellular amastigote. 

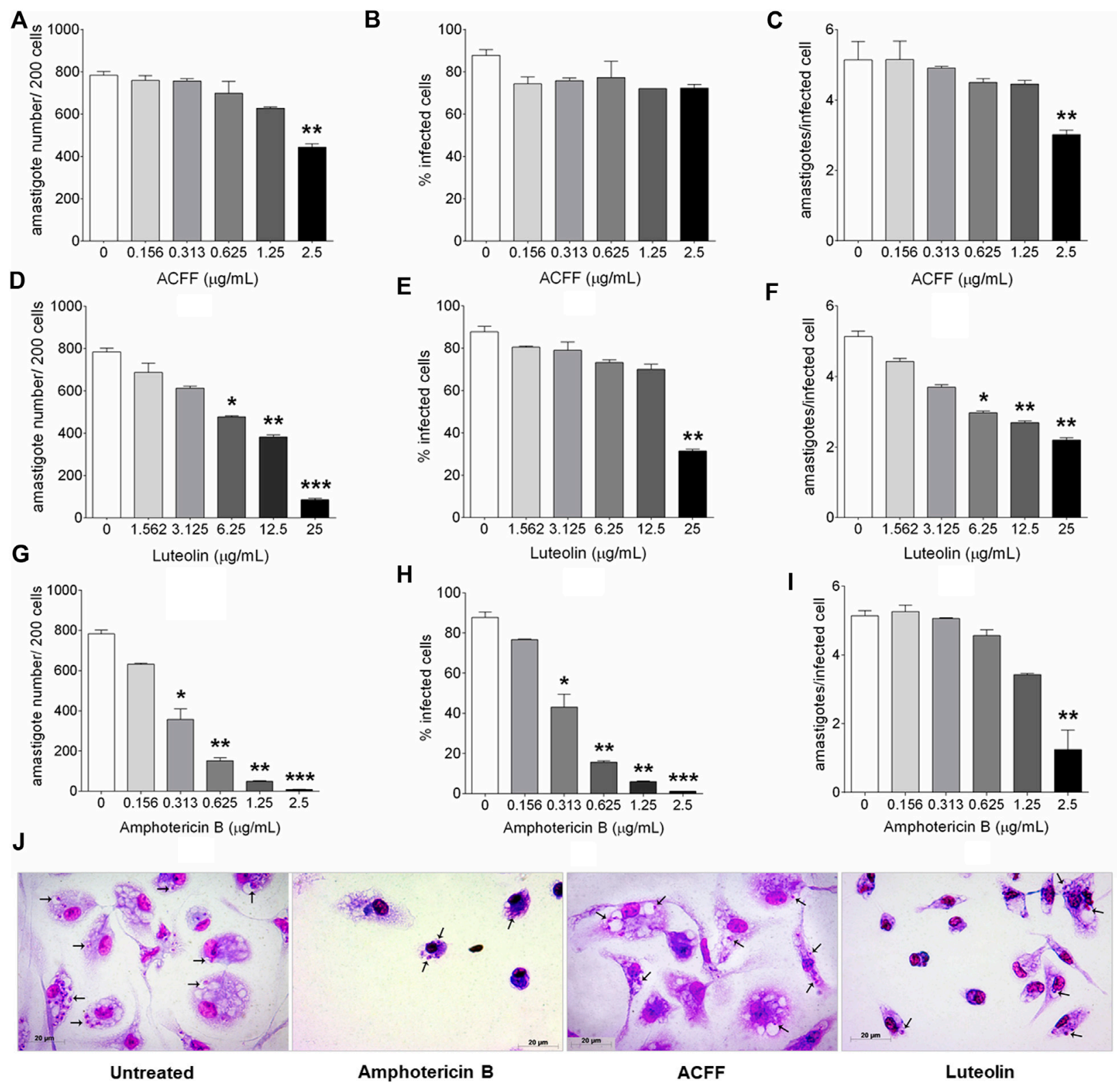

FIGURE 3 | BALB/c peritoneal macrophages infected with Leishmania amazonensis and treated for $24 \mathrm{~h}$ with amphotericin B, Arrabidaea chica flavone-rich fraction (ACFF) or luteolin. (A-I) Parameters of infection and (J) light microscopy of untreated, and treated with amphotericin B (2.5 $\mu \mathrm{g} / \mathrm{mL})$, ACFF (2.5 $\mu \mathrm{g} / \mathrm{mL})$ or luteolin $(25 \mu \mathrm{g} / \mathrm{mL})$ infected cells. (black arrows) Intracellular amastigotes inside macrophages. The images and data (mean \pm standard deviation) represent two independent experiments performed in triplicate. ${ }^{*} p<0.05,{ }^{* *} p<0.01$ and ${ }^{* * *} p<0.001$ when compared with untreated infected cells by Kruskal-Wallis and Dunn's multiple comparison test. Giemsa, 40x objective.

The parameters of infection of untreated cells were used as comparative control for the treatment with the different compounds at different concentrations. Infected and untreated macrophages presented $783.1 \pm 80.43$ amastigotes per 200 cells, $87.74 \pm 7.95 \%$ of infected cells, and mean of amastigotes per infected cell of $5.135 \pm 0.53$ (Figure 3). The treatment with ACFF significantly reduced the number of amastigotes per 200 cells $(443.50 \pm 30.60, p=0.0010$, Figure $3 \mathrm{~A})$ and the mean of amastigotes per infected cell $(3.19 \pm 0.21, p=0.0043$, Figure $3 \mathrm{C}$ ) at $2.5 \mu \mathrm{g} / \mathrm{mL}$. In infected cells treated with luteolin, a statistically significant reduction was observed at the highest concentration evaluated $(25 \mu \mathrm{g} / \mathrm{mL})$ in all parameters of infection according to the intracellular amastigote number $(84.50 \pm 13.28$, $p=0.0002$, Figure 3D), percentage of infected cells ( $31.50 \pm 1.73$, $p=0.0011$, Figure 3E), and the mean of amastigotes per infected cell $(2.20 \pm 0.10, p=0.0049$, Figure 3F). Amphotericin B showed a statistically significant reduction in all infection parameters at $2.5 \mu \mathrm{g} / \mathrm{mL}(9.00 \pm 1.73, p=0.0005$, Figure 3G; $1.09 \pm 0.21, p=$ 0.0002 , Figure $3 \mathrm{H} ; 1.25 \pm 1.37, p=0.0002$, Figure 3I). As shown in Figure 3J, images of BALB/c peritoneal macrophages infected 


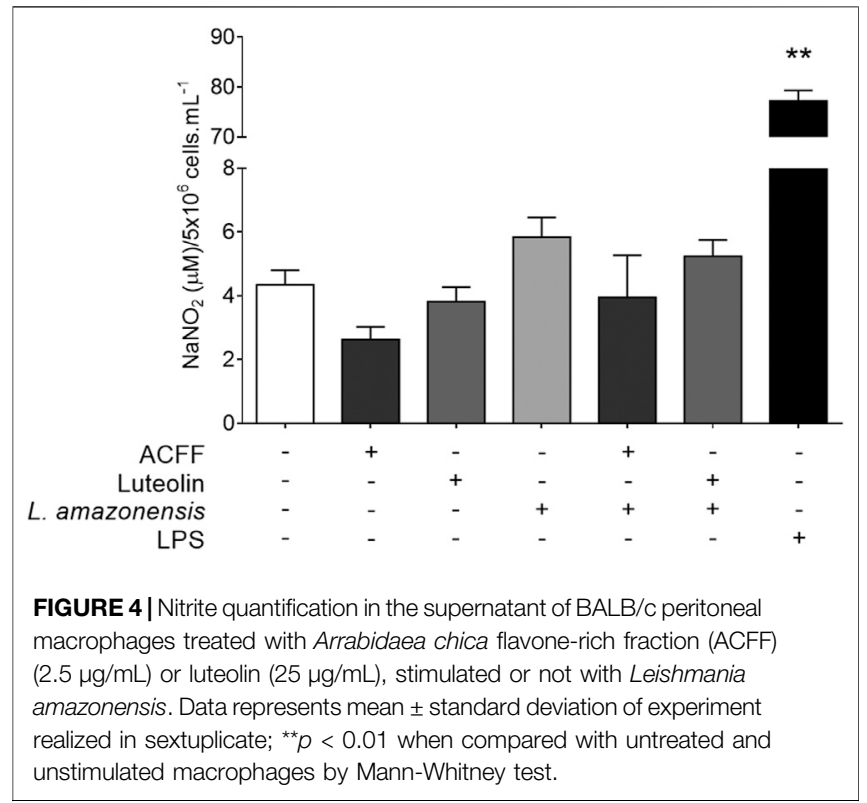

with L. amazonensis and treated with amphotericin B, ACFF and luteolin corroborate with the results of Figures 3A-I.

\section{Nitrite Quantification in $L$. amazonensis-Infected Peritoneal Macrophages Treated With ACFF and Luteolin}

The effect of $A$. chica compounds on nitrite production in the supernatant of $\mathrm{BALB} / \mathrm{c}$ peritoneal macrophages is shown in Figure 4. The macrophages showed low nitrite levels in cells treated with ACFF $(2.63 \pm 0.79 \mu \mathrm{M} \mathrm{NaNO}, p=0.0857)$ and luteolin $\left(3.55 \pm 0.91 \mu \mathrm{M} \mathrm{NaNO}_{2}, p=0.4000\right)$, when compared to untreated cells $\left.(4.34 \pm 1.12 \mu \mathrm{M} \mathrm{NaNO})_{2}\right)$. Low nitrite levels were also observed in cells stimulated with L. amazonensis and treated with ACFF $(3.34 \pm 2.65 \mu \mathrm{M} \mathrm{NaNO}, p=0.4476)$ and luteolin $(4.43 \pm 0.30 \mu \mathrm{M} \mathrm{NaNO}, p=0.4048)$, when compared to stimulated and untreated cells $\left(5.83 \pm 1.69 \mu \mathrm{M} \mathrm{NaNO}_{2}\right)$, although the difference was not statistically significant. In the test, macrophages when stimulated with lipopolysaccharide (LPS) produced high levels of nitrite compared to cultures not stimulated with LPS.

\section{Flavones From A. chica Promotes Ultrastructural Changes in $L$. amazonensis Promastigotes}

To assess whether the treatment with compounds from A. chica promoted morphological and structural changes, analysis by transmission electron microscopy (TEM) was performed. Parasites were treated or not with ACFF and luteolin $\mathrm{IC}_{50}$ for $24 \mathrm{~h}$. Promastigote forms showed the cellular morphology with an elongated body and all its intact organelles (Figure 5A). It was possible to observe that the treatment with ACFF promoted several vacuoles containing granular, circular and electron-

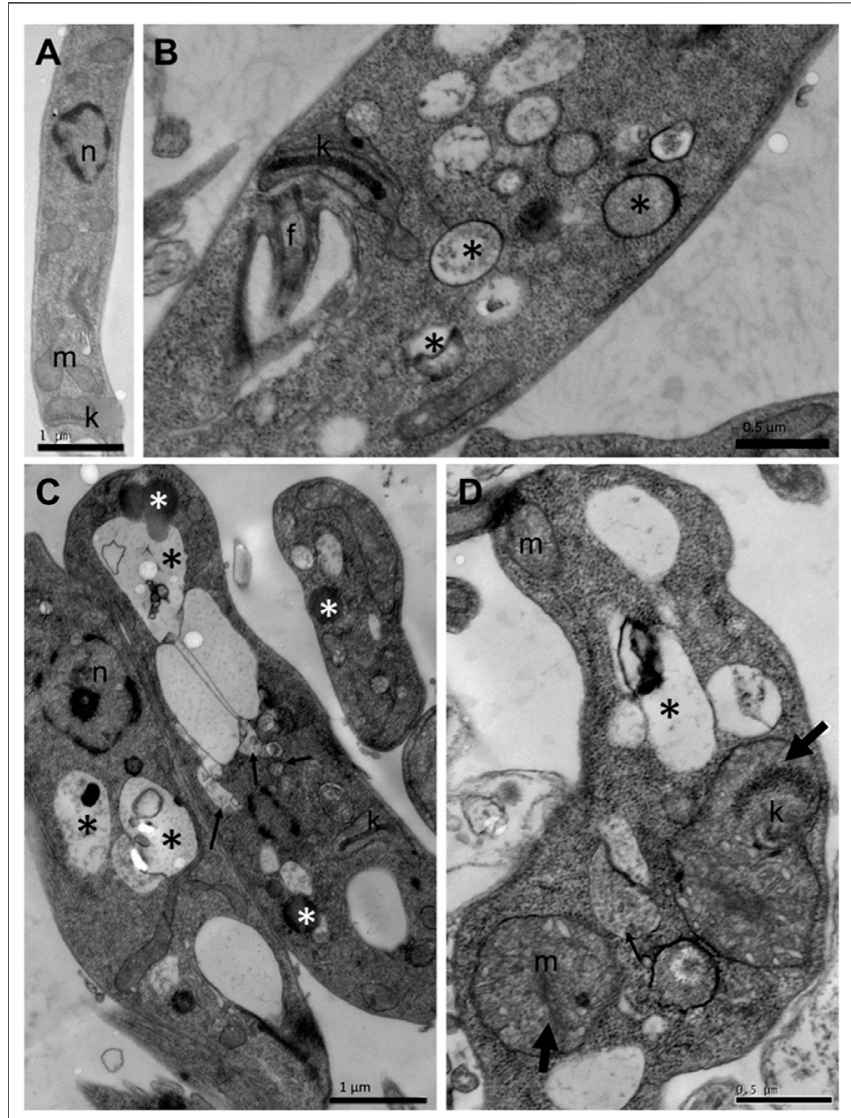

FIGURE 5 | Transmission electron microscopy of Leishmania amazonensis promastigote forms. (A) Untreated parasites. (B-D) Parasites were treated with Arrabidaea chica flavone-rich fraction (ACFF) at $2.5 \mu \mathrm{g} / \mathrm{mL}$ for $24 \mathrm{~h}$. Several vacuoles containing granular, circular, and electrondense material dispersed by the cytoplasm (black asterisks); lipid bodies; multivesicular bodies (thin arrows); swelling of kinetoplast and mitochondria with breakdown of mitochondrial cristae (thick arrow). n: nucleus; m: mitochondria; k: kinetoplast; f: flagellum.

dense material dispersed by the cytoplasm (Figure 5B), lipid bodies, multivesicular bodies (Figure 5C), swelling of kinetoplast and mitochondria with the breakdown of mitochondrial cristae (Figure 5D). Luteolin promoted small vacuoles containing electron-dense microvesicles dispersed in the cytoplasm (Figures 6A,B), change in the nuclear chromatin (Figure 6A), lipid bodies (Figures 6A,B), kinetoplast and mitochondria fully degenerated (Figures 6A,B). Also, it was possible to observe that luteolin promoted vacuoles containing material of different shapes and density, lipid bodies (Figures 7A-D), several layers of circular membranes involving multivesicular bodies (Figure 7B), and autophagosome-like vacuoles (Figure 7D).

\section{DISCUSSION}

Dichloromethane fraction obtained from hydroalcoholic extract of $A$. chica is admittedly rich in flavonoids (Takemura et al., 1995; 

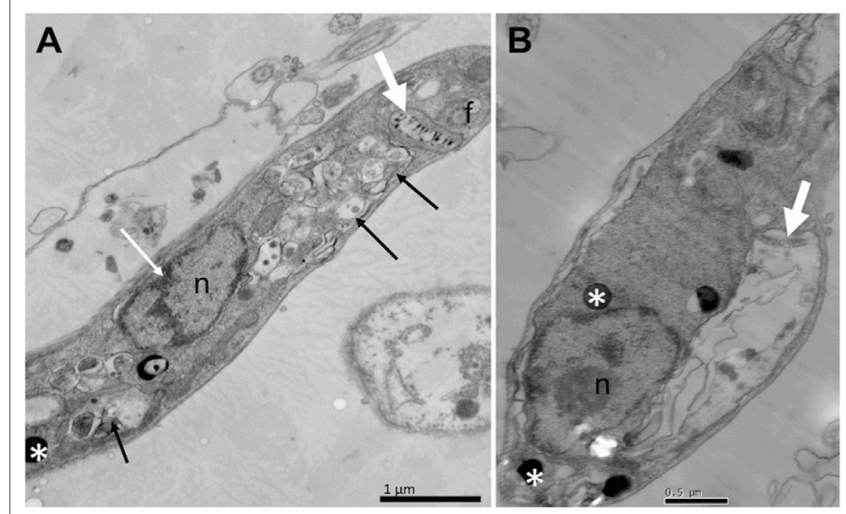

FIGURE 6 | Ultrastructural alterations of Leishmania amazonensis promastigote forms treated with luteolin at $25 \mu \mathrm{g} / \mathrm{mL}$ for $24 \mathrm{~h}$. Small vacuoles containing electron-dense microvesicles dispersed by the cytoplasm (arrows), change in the nuclear chromatin (white arrow) (A); lipid bodies (white asterisks), kinetoplast and mitochondria fully degenerated (white thick arrows) (A-B). n: nucleus; f: flagellum

Zorn et al., 2001; Devia et al., 2002; Barbosa et al., 2008; Siraichi et al., 2013), among which stand out anthocyanidins, the chemical markers of the species, in addition to flavones and flavonols. The fractionation carried out in this study had as the main objective obtaining a flavone-rich fraction, without anthocyanidins, and the isolation of some major compounds.

HPLC-DAD-UV analysis showed a chromatogram with six peaks. UV/Vis spectrum showed that the six compounds had broad bands of absorption with maximum peaks in the range of 338 and $348 \mathrm{~nm}$ (band I) and 256 and $283 \mathrm{~nm}$ (band II). Band I is associated with absorption due to the $\mathrm{B}$ ring of cinnamoyl system and when registered in the range of $304-350 \mathrm{~nm}$ it is characteristic of flavones (Mabry et al., 1970). Band II is related to absorption in the A ring benzoyl system. This ring when trisubstituted shows higher absorption at band II (Supplementary material-S1).

The flavone-rich fraction (ACFF) was also analyzed by LCESI-MS-MS, whose results compared with literature data (Siraichi et al., 2013; Grabsk et al., 2017) allowed to identify four flavonoids: 6-hydroxy-luteolin (3), scutellarein (4), carajuflavone (5) and chrysoeriol (6).

Mass spectrometry has been an extremely useful method to identify and characterize polyphenolic secondary plant metabolites, and flavonoids are of particular importance (Cuyckens and Claeys, 2004). The collision of the precursor ions produced in the positive ion mode from the detected flavones yielded mass spectra for product ions. These spectra were used for their structural identification. The most useful fragmentations in terms of flavonoid aglycone identification are those that require cleavage of two carbon-carbon bonds of the flavonoid $\mathrm{C}$ ring (dihydropyran ring), which can be rationalized in terms of retro-Diels-Alder reactions (Pinheiro and Justino, 2012; Vaca et al., 2017). Such fragmentation in general allows a quick identification of the flavonoid type, as well as the number of substituents in each ring (Pinheiro and Justino, 2012). Therefore, in positive mode, fragments at $m / z 153$ and 169 are characteristic

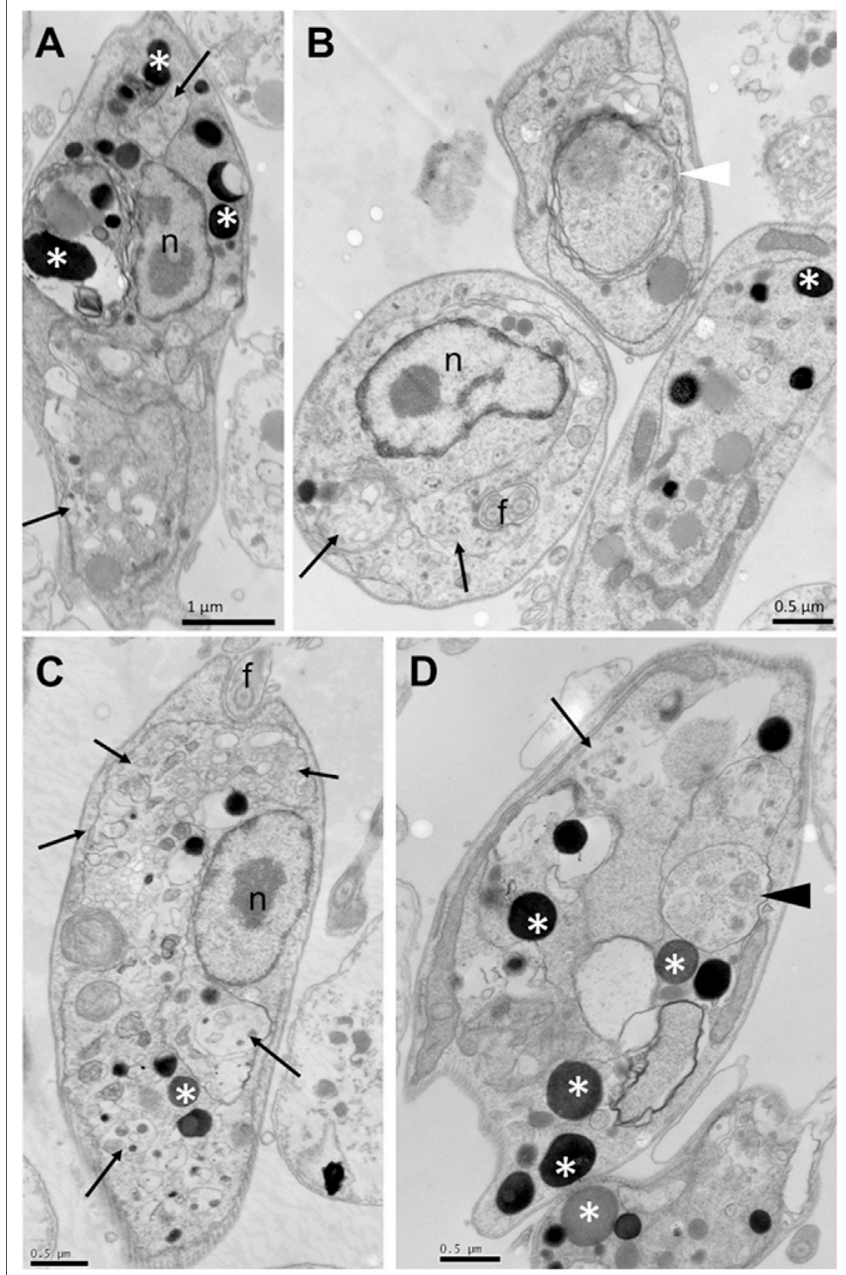

FIGURE 7 | Ultrastructural alterations of Leishmania amazonensis promastigote forms treated with luteolin at $25 \mu \mathrm{g} / \mathrm{mL}$ for $24 \mathrm{~h}$. Vacuoles containing material of different shapes and density (arrows), lipid bodies (white asterisks) (A-D), several layers of circular membranes involving multivesicular bodies (white arrowhead) (B), autophagosome-like vacuoles (black arrowhead) (D). n: nucleus.

of compounds containing di-hydroxylated and tri-hydroxylated A ring, respectively. Retro-Diels-Alder fragmentation also produces information about B ring. Fragments at $m / z 119$ and 135 are related to mono- and di-hydroxylated $\mathrm{B}$ ring, respectively. Positive LC-ESI-MS-MS data analyses were performed to confirm structures in addition to data already obtained in HPLC-DADUV and Rt of flavones from ACFF. Both luteolin (1) and apigenin (2) have been identified by ${ }^{1} \mathrm{H}$ NMR and ${ }^{13} \mathrm{C}$ NMR spectrometric techniques, UV, elution order, and Rt, and were also evaluated by fragmentation pattern. These compounds showed the RetroDiels-Alder fragmentation pattern confirming the dihydroxylation of A ring (ions at $\mathrm{m} / z 153.0151$ and 153.0148, respectively). Luteolin (1) showed experimental pseudomolecular ion $\left(\mathrm{M}+[\mathrm{H}]^{+}\right)$at $\mathrm{m} / z$ 287.0496, which is compatible to the molecular formula $\mathrm{C}_{15} \mathrm{H}_{10} \mathrm{O}_{6}$ as well as the mass fragment at $\mathrm{m} / z 241.0447\left[\left(\mathrm{M}-\mathrm{H}_{2} \mathrm{O}-\mathrm{CO}\right)\right]^{+}$. Apigenin (2) 
was confirmed by the pseudo-molecular ion at $\mathrm{m} / \mathrm{z} 271.0548$, corresponding to the molecular formula $\mathrm{C}_{15} \mathrm{H}_{10} \mathrm{O}_{5}$, as well as the fragments at $m / z 243$ characterized by $\mathrm{C}=\mathrm{O}$ loss. Retro-DielsAlder fragments correspondent to a tri-hydroxylated A ring at $m$ / $z 169.0103$ and 169.0105 were observed to 6-hydroxy-luteolin (3) and scutellarein (4), respectively. The compound 6-hydroxyluteolin or 5,6,7,3', $4^{\prime}$-penta-hydroxy flavone (3) also showed the experimental pseudo-molecular ion $\left(\mathrm{M}+[\mathrm{H}]^{+}\right)$at $\mathrm{m} / z$ 303.0449, compatible to the molecular formula $\mathrm{C}_{15} \mathrm{H}_{11} \mathrm{O}_{7}$, as well as the mass fragment at $m / z 257.0389\left[\left(\mathrm{M}-\mathrm{H}_{2} \mathrm{O}-\mathrm{CO}\right)\right]^{+}$, confirming their identification. The structure of scutellarein (4) was also confirmed by the experimental pseudo-molecular ion at $\mathrm{m} / \mathrm{z} 287.0496$, which is compatible with the molecular formula $\mathrm{C}_{15} \mathrm{H}_{10} \mathrm{O}_{6}$. Carajuflavone or $6,7,3^{\prime}, 4^{\prime}$-tetrahydroxy-5-methoxy flavone (5) showed a pseudo-molecular ion at $\mathrm{m} / z 317.0595$ corresponding to the molecular formula $\mathrm{C}_{16} \mathrm{H}_{13} \mathrm{O}_{7}$. The fragment at $\mathrm{m} / z 168.0017$ indicated that in Retro-Diels-Alder fragmentation, one of the three hydroxyl groups of A ring was substituted. It was confirmed by their fragmentation pattern that produced ions at $\mathrm{m} / \mathrm{z} 302.0360$ confirming the loss of a methyl group $\left(\mathrm{M}-\left[\mathrm{CH}_{3}\right]^{+}\right)$. Chrysoeriol (6) showed experimental pseudo-molecular ion at $\mathrm{m} / z 301.0646$ compatible with the molecular formula $\mathrm{C}_{16} \mathrm{H}_{13} \mathrm{O}_{6}$. Chrysoeriol fragmentation pattern produced ions at $\mathrm{m} / z 286.0414\left[(\mathrm{M})-\mathrm{CH}_{3}\right]^{+}$and at $\mathrm{m} / z$ $258.0467\left[(\mathrm{M})-\mathrm{CH}_{3}-\mathrm{CO}\right]^{+}$. These pieces of evidence confirm compound (6) as chrysoeriol (Supplementary Material S2).

All identified flavones in ACFF have been previously described for A. chica. Compound 6-hydroxy-luteolin, besides of luteolin, apigenin, and chrysoeriol had been described for $A$. chica leaves hydroethanolic extract (Vasconcelos et al., 2019). In another study, also with an A. chica extract, Siraichi et al. (2013) identified six flavones, from which, four-6-hydroxyluteolin (3), luteolin (1), apigenin (2), and scutellarein (4)-were identified in ACFF. Carajuflavone (5), another 6-hydroxylated compound from $A$. chica had already been described by Takemura et al. (1995). Compound 6-hydroxy-luteolin (3) has been reported in the Bignoniaceae family, and 6-hydroxylation is a common structural feature of the Bignoniaceae flavonoids having particular chemotaxonomy relevance for this reason. Besides, 6-hydroxylation is also characteristic of the structures of the red pigments anthocyanidins carajurin and carajurone found in A. chica (Harborne, 1967).

Quantitative analysis showed luteolin (1) as the most representative flavone of ACFF (Figure 1), whose concentration was calculated as $190.7 \mathrm{mg} / \mathrm{g}$ dry extract. Apigenin (2) represented only $12.43 \mathrm{mg} / \mathrm{g}$ dry extract. The results obtained in the present study are already better than other publications on concentrations and contents of luteolin and apigenin in extracts obtained from A. chica leaves (Paula et al., 2013). It demonstrated that the developed method for obtaining the flavone-rich fraction showed great results.

Publications by our research network previously reported on the leishmanicidal activity of hydroalcoholic extracts from four morphotypes of A chica (Moragas-Tellis et al., 2020). However, as the species $A$. chica exhibit a great set of polyphenolic compounds-mainly flavonoids-we decided to expand this study, previously done only with anthocyanidins, to evaluate whether flavones may also be involved in the leishmanicidal activity.

The increase in antipromastigote activity from bioguided fractionation facilitated the identification of the best fractionation stage that contributes to the best results for leishmanicidal activity. As a result, the ACFF was more effective than ACCE, and the isolated flavone luteolin showed better activity than ACFF. Apigenin, however, showed activity similar to ACFF.

Studies conducted by Cortez de Sá et al. (2015) presented a screening test for the crude ethanolic extract of the leaves of $A$. chica with the inhibitory concentration of $50 \%\left(\mathrm{IC}_{50}\right)$ of the promastigote forms of L. amazonensis determined at $155.9 \mu \mathrm{g} / \mathrm{mL}$. Phytochemical screening of that study showed an extract containing flavonoids, phenolic compounds, tannins, anthocyanidins and chalcones. In addition, the crude extract of the leaves of $A$. chica had a cytotoxic effect at a concentration of $189.9 \mu \mathrm{g} / \mathrm{mL}$. Factors that can explain the difference in phytochemical and biological results are probably due to the climatic differences between the two locations where the plant was collected, as well as the way of obtaining the extract (Cortez de Sá et al., 2015). However, it should be noted that the difference in cytotoxicity found with our study is probably related to the exposure time used, since we used $72 \mathrm{~h}$, while in the study by Cortez de Sá et al. (2015) the time was reduced to $24 \mathrm{~h}$. Besides, and even more important, the different morphotypes of $A$. chica vary in chemical composition and, consequently, in biological activity (Moragas-Tellis et al., 2020).

Aware that the extraction and fractionation methods can help in biological activity, we opted to optimize the bioguided fractionation process favoring the obtaining of a flavone-rich fraction in an attempt to better explore the phytochemical profile of $A$. chica species. Flavones have demonstrated a wide range of biological activities that include antioxidant, antimicrobial, antiinflammatory and other activities. In addition, structure-activity relationships have generated interest among medicinal chemists, making the flavones an important class of natural products of new therapeutic agents (Singh et al., 2014).

Literature data show flavones with leishmancidal activity. Apigenin was tested for its anti-Leishmania activity against the promastigote forms of L. amazonensis, inhibiting the growth of the parasites at $\mathrm{IC}_{50}$ values of $23.7 \mu \mathrm{M}$ (Fonseca-Silva et al., 2015) and $22.77 \mu \mathrm{M}$ against Leishmania donovani strains (Antwi et al., 2019). This inhibition was also observed by luteolin at IC $_{50}$ value of $12.5 \mu \mathrm{M}$ against L. donovani (Mittra et al., 2000). Another study shows apigenin and luteolin having inhibitory activity against $L$. donovani axenic amastigotes $\left(\mathrm{IC}_{50} 1.9\right.$ and $0.8 \mu \mathrm{g} /$ $\mathrm{mL}$, respectively) (Tasdemir et al., 2006). The antipromastigote activity of the ACFF may be related to the high concentration of these flavones in their composition. The high cytotoxicity of these flavones against L6 cells (derived from rat skeletal myoblasts) has also been reported, at $\mathrm{IC}_{50}$ values of $18.1 \mu \mathrm{g} /$ $\mathrm{mL}$ for apigenin and $9.44 \mu \mathrm{g} / \mathrm{mL}$ for luteolin-data that corroborate the toxicity observed in our study. Besides, the structure-activity relationship of these flavones was investigated, and it was observed that the presence of the 5,7-dihydroxybenzochromone structure greatly increases 
leishmanicidal activity, occurring the same with the presence of the double bond between positions 2 and 3 (C-2,3). Such characteristics are observed in apigenin and luteolin. Thus, it is possible to infer that the different leishmanicidal activity of these two flavones might be due to the replacement pattern in the B-ring, since luteolin has a catechol portion $\left(3^{\prime}, 4^{\prime}\right.$ dihydroxyphenyl) while apigenin has only one hydroxyl in 4' (Tasdemir et al., 2006).

Our findings against the promastigote form recommend selecting the ACFF and luteolin, the main component of the fraction-to verify the activity against the forms of $L$. amazonesis intracelular amastigote. In the search for new drugs against Leishmania spp., intracellular amastigote is the stage of the parasite considered as the most relevant target for the primary screening of new compounds (de Muylder et al., 2011), and the most consistent indicator of in vivo activity (Croft, 1986), additionally considered "the gold standard" of in in vitro studies (Baek et al., 2020). It is therefore of interest to test the effectiveness of $A$. chica compounds in intracellular amastigotes.

It was possible to observe an improvement in the leishmancidal activity, being ACFF and luteolin 11.3 and 2.67 times more active against intracellular amastigote forms than to the promastigotes forms, respectively. A study performed by Wong et al. (2012) reported that luteolin exhibited promising activity only against the intracellular amastigote, but not for extracellular promastigotes, suggesting that its specific targets are present only in the intracellular phase. This activity is also observed in another study against $L$. donovani, according to which luteolin reduced intracellular amastigote load by $70 \%$ at a final concentration as low as $12.5 \mu \mathrm{M}$ (Mittra et al., 2000). Therefore, the high concentration of luteolin in ACFF may be responsible for the increased inhibition against the intracellular forms of the parasite.

When comparing the results of the activity against the intracellular phase, ACFF was 3.2 times more active than luteolin. It is worth mentioning that another flavone present in the ACFF composition was apigenin, but this compound was not tested against the intracellular amastigote form due to its low yield. However, data from the literature show the significant inhibitory effect of apigenin against the intracellular amastigote forms of $L$. donovani, at $\mathrm{IC}_{50}$ values of $45.66 \pm 0.01 \mu \mathrm{M}(12.34 \mu \mathrm{g} /$ $\mathrm{mL})$. In addition, when the infected macrophages were treated with increasing concentrations of apigenin, there was a decrease in the number of infected cells (Antwi et al., 2019). Therefore, this leads us to infer that the presence of a couple of compounds in the ACFF can contribute to the leishmanicidal activity and to lower cytotoxic effect, favoring the greater selectivity to the parasite observed to ACFF when compared to luteolin. These findings are often considered to be the result of a synergistic or additive effect of the extract's constituents (Dalby-Brown et al., 2005).

The inhibition of intracellular amastigote is directly related to the presence of nitric oxide (NO) in activated macrophages (Mukbel et al., 2007). Therefore, in an attempt to understand the leishmanicidal activity of ACFF and luteolin against intracellular amastigote forms, nitrite quantification was performed as an indirect way to determine NO levels
(Almeida-Souza et al., 2016). However, there were no significant changes in this assessment parameter.

In a study with apigenin and luteolin, both inhibited $\mathrm{NO}$ production, considering that a C-2,3 double bond may be important, and that the patterns of substitution of flavonoid molecules can determine the potency of the inhibition in NO production (Kim et al., 1999). In addition, suppression in the production of NO and prostaglandin E2 (PGE2), without having cytotoxicity in RAW 264.7 mouse macrophage cells activated by bacterial lipopolysaccharide was also observed when exposed to flavones, luteolin and its luteolin-7-O-glucoside. The suppression of inducible nitric oxide synthase (iNOS) and the expression of cyclooxygenase-2 protein (COX-2) are responsible for the inhibitory effects, and not for the reduction of enzymatic activity (Hu and Kitts, 2004). Different culture conditions and cell types may also be responsible for some difference between data in the literature and the results of the present study. Therefore, other mechanisms may be involved in the leishmanicidal activity of $A$. chica flavonoids against intracellular amastigote.

Trying to understand the leishmanicidal effect of $A$. chica compounds directly on the parasite, ultrastructural evaluation of the promastigote forms of $L$. amazonensis was performed by transmission electron microscopy. The treatment with ACFF promoted ultrastructural alterations such as the vacuolization process of the cytoplasm, lipid and multivesicular bodies, swelling of the kinetoplast and mitochondria with the breaking of the mitochondrial ridges. Ultrastructural changes were also observed in the study by Rodrigues et al. (2014), with L. infantum promastigotes treated with fraction B2 (1:1 n-hexane/ethyl acetate) obtained from the crude hexane extract of $A$. chica. In this study, mitochondrial edema with loss of matrix content and the presence of vesicles within this organelle were observed.

Luteolin, the metabolite with the highest concentration in ACFF composition, was evaluated for ultrastructural alterations induced in L. amazonensis promastigotes. It was possible to observe vacuolization of the cytoplasm, change in nuclear chromatin, lipid bodies, with kinetoplast and fully degenerated mitochondria, and vacuoles similar to autophagosomes. Studies performed by Mittra et al. (2000) indicates that flavonoids may target the enzyme topoisomerase II in the kinetoplast of parasites, since it reports that luteolin and quercetin induce significant cleavage of the topoisomerase II-mediated kDNA minicircle in Leishmania, an inhibition similar to the well-known antiLeishmania drug, pentamidine. Another study elucidates the mechanism of action of luteolin by analyzing mitochondrial and cytosolic changes associated with death similar to $L$. donovani cell apoptosis (Sen et al., 2006). In this work, Sen et al. (2006) reports that luteolin inhibition of the production of glycolytic ATP was an essential event responsible for the depolarization of the mitochondrial membrane in depleted $\mathrm{mt}$ DNA cells to propagate apoptosis-like death in Leishmania cells.

Our results provide additional evidence on the antileishmanial activity induced by A. chica. However, based on the findings obtained, further studies should be carried out to elucidate the mechanisms of action, as well as in vivo studies are essential to assess the leishmanicidal activity of the ACFF against Leishmania. 


\section{CONCLUSION}

Chromatographic techniques and analysis of the mass spectra obtained from the ACCE allowed the identification of compounds of the ACFF derived from A. chica. The flavones luteolin and apigenin were isolated from the ACFF using chromatographic techniques and identified by NMR spectrometry techniques. ACCE, ACFF and flavones showed leishmanicidal activity against the promastigotes of L. amazonensis. The antiparasitic effect of ACFF and luteolin was confirmed by the ultrastructural changes with induction of mitochondrial damage. ACFF also showed low cytotoxicity in host cells if compared with the isolated flavones. ACFF and luteolin showed leishmanicidal activity against the intracellular amastigotes, however, this activity is not related to the production of NO by host cells. Thus, ACFF is a suitable candidate for further in vivo investigations against L. amazonensis.

\section{DATA AVAILABILITY STATEMENT}

All datasets presented in this study are included in the article/ Supplementary Material.

\section{ETHICS STATEMENT}

The animal study was reviewed and approved by the Ethics Committee on Animal Care and Utilization of Oswaldo Cruz Institute (CEUA-IOC L53/2016).

\section{REFERENCES}

Almeida-Souza, F., de Oliveira, A. E. R., Abreu-Silva, A. L., and da Silva Calabrese, K. (2018). In Vitro activity of Morinda citrifolia Linn. Fruit Juice against the Axenic Amastigote Form of Leishmania Amazonensis and its Hydrogen Peroxide Induction Capacity in BALB/c Peritoneal Macrophages. BMC Res. Notes 11, 492-497. doi:10.1186/s13104-018-3555-7

Almeida-Souza, F., de Souza, C. d. S. F., Taniwaki, N. N., Silva, J. J. M., de Oliveira, R. M., Abreu-Silva, A. L., et al. (2016). Morinda citrifolia Linn. Fruit (Noni) Juice Induces an Increase in NO Production and Death of Leishmania Amazonensis Amastigotes in Peritoneal Macrophages from BALB/c. Nitric Oxide 58, 51-58. doi:10.1016/j.niox.2016.06.004

Almeida-Souza, F., Silva, V. D. d., Silva, G. X., Taniwaki, N. N., Hardoim, D. d. J., Buarque, C. D., et al. (2020). 1,4-Disubstituted-1,2,3-Triazole Compounds Induce Ultrastructural Alterations in Leishmania Amazonensis Promastigote: An In Vitro Antileishmanial and In Silico Pharmacokinetic Study1, 4-Disubstituted-1, 2, 3-Triazole Compounds Induce Ultrastructural Alterations in Leishmania Amazonensis Promastigote: An In Vitro Antileishmanial and In Silico Pharmacokinetic Study. Ijms 21, 6839. doi:10.3390/ijms21186839

Antwi, C. A., Amisigo, C. M., Adjimani, J. P., and Gwira, T. M. (2019). In Vitro activity and Mode of Action of Phenolic Com. Pounds Leishmania Donovaniplos Negl. Trop. Dis. 13, e0007206. doi:10.1371/journal.pntd.0007206

Aro, A. A., Simões, G. F., Esquisatto, M. A. M., Foglio, M. A., Carvalho, J. E., Oliveira, A. L. R., et al. (2013). Arrabidaea Chica Extract Improves Gait Recovery and Changes Collagen Content during Healing of the Achilles Tendon. Injury 44, 884-892. doi:10.1016/j.injury.2012.08.055

Baek, K.-H., Piel, L., Rosazza, T., Prina, E., Späth, G. F., and No, J. H. (2020). Infectivity and Drug Susceptibility Profiling of Different Leishmania-Host Cell Combinations. Pathogens 9, 393. doi:10.3390/pathogens 9050393

\section{AUTHOR CONTRIBUTIONS}

JS, CM, MC, PS, CS and DH performed the experiments. MB, $\mathrm{KC}$ and FA contributed to conception and design of the study. NT obtained TEM images. JS, DM and FA organized the database. JS and FA performed the statistical analysis. JS and $\mathrm{CM}$ wrote the first draft of the manuscript. All authors contributed to manuscript revision, read, and approved the submitted version.

\section{FUNDING}

This study was partially supported by the Coordination for the Improvement of Higher Education Personnel (Coordenação de Aperfeiçoamento de Pessoal de Nível Superior - CAPES) Finance Code 001; and by the Carlos Chagas Filho Foundation for Research Support of the State of Rio de Janeiro (FAPERJ), grant number E-26/210.344/2019 and E-26/201.765/2019. Dr Fernando Almeida-Souza is a postdoctoral research fellow and scholarship holder of CAPES, grant number 88887.363006/ 2019-00.

\section{SUPPLEMENTARY MATERIAL}

The Supplementary Material for this article can be found online at: https://www.frontiersin.org/articles/10.3389/fphar.2021.703985/ full\#supplementary-material

Barbosa, W. L. R., Pinto, L. d. N., Quignard, E., Vieira, J. M. d. S., Silva Jr., J. O. C., Albuquerque, S., et al. (2008). Arrabidaea Chica (HBK) Verlot: Phytochemical Approach, Antifungal and Trypanocidal Activities. Rev. Bras. Farmacogn. 18, 544-548. doi:10.1590/S0102-695X2008000400008

Behrens, M. D., Tellis, C. J. M., and ChagasdS, M. d. S. (2012). Arrabidaea Chica (Humb. \& Bonpl.) B. Verlot (Bignoniaceae). Fitos 7, 236-244. doi:10.32712/ 2446-4775.2012.165

Bieski, I. G. C., Rios Santos, F., De Oliveira, R. M., Espinosa, M. M., Macedo, M., Albuquerque, U. P., et al. (2012). Ethnopharmacology of Medicinal Plants of the Pantanal Region (Mato Grosso, Brazil). Evid. Based. Complement. Alternat. Med. 2012, 272749. doi:10.1155/2012/272749

Corrêa, M. P. (1984). Dicionário das Plantas úteis do Brasil e das Exóticas Cultivadas Rio de Janeiro: Ministeŕioda Agricultura, Instituto Brasileiro de Desenvolvimento Florestal.

Cortez de Sá, J., Almeida-Souza, F., Mondêgo-Oliveira, R., da Silva Oliveira, I. d. S., Lamarck, L., Magalhães, I. d. F. B., et al. (2015). Leishmanicidal, Cytotoxicity and Wound Healing Potential of Arrabidaea Chica Verlot. BMC Complement. Altern. Med., 16, 1-11. doi:10.1186/s12906-015-0973-0

Croft, S. L. (1986). In Vitro screens in the Experimental Chemotherapy of Leishmaniasis and Trypanosomiasis. Parasitol. Today 2, 64-69. doi:10.1016/ 0169-4758(86)90157-2

Cuyckens, F., and Claeys, M. (2004). Mass Spectrometry in the Structural Analysis of Flavonoids. J. Mass. Spectrom. 39, 1-15. doi:10.1002/jms.585

da Silva, B. J. M., Hage, A. A. P., Silva, E. O., and Rodrigues, A. P. D. (2018). Medicinal Plants from the Brazilian Amazonian Region and Their Antileishmanial Activity: a Review. J. Integr. Med. 16, 211-222. doi:10.1016/j.joim.2018.04.004

Dalby-Brown, L., Barsett, H., Landbo, A.-K. R., Meyer, A. S., and Mølgaard, P. (2005). Synergistic Antioxidative Effects of Alkamides, Caffeic Acid Derivatives, and Polysaccharide Fractions fromEchinacea Purpureaon In Vitro Oxidation of Human Low-Density Lipoproteins. J. Agric. Food Chem. 53, 9413-9423. doi:10.1021/jf0502395 
de Muylder, G., Ang, K. K. H., Chen, S., Arkin, M. R., Engel, J. C., and McKerrow, J. H. (2011). A Screen against Leishmania Intracellular Amastigotes: Comparison to a Promastigote Screen and Identification of a Host Cellspecific Hit. Plos Negl. Trop. Dis. 5, e1253. doi:10.1371/journal.pntd.0001253

Devia, B., Llabres, G., Wouters, J., Dupont, L., Escribano-Bailon, M. T., PascualTeresa, S. d., et al. (2002). New 3-deoxyanthocyanidins from Leaves of Arrabidaea chicaNew 3-deoxyanthocyanidins from Leaves of Arrabidaea Chica. Phytochem. Anal. 13, 114-120. doi:10.1002/pca.632

do Amaral, R. R., Santos, A. A., Saravia, A., Botas, G., Cruz, R. A., Fernandes, C. P., et al. (2012). Biological Activities of Arrabidaea Chica (Bonpl.) B. Verl. Leaves. Lat. Am. J. Pharm. 31, 451-455.

dos Santos, V. C., Longo, T. B., Garcia, A. L. H., Richter, M. F., Guecheva, T. N., Henriques, J. A. P., et al. (2013). Evaluation of the Mutagenicity and Genotoxicity of Arrabidaea Chica Verlot (Bignoneaceae), an Amazon Plant with Medicinal Properties. J. Toxicol. Environ. Health Part. A. 76, 381-390. doi:10.1080/15287394.2012.761947

Ersöz, T., Harput, Ü. Ș., Saracoğlu, İ., Çaliș, İ., and Ogihara, Y. (2002). Phenolic Compounds from Scutellaria Pontica. Turkish J. Chem. 26, 581-588.

Evangelista, S. S., Sampaio, F. C., Parente, R. C., and Bandeira, M. F. C. L. (2013). Fitoterápicos na odontologia: estudo etnobotânico na cidade de Manaus. Rev. Bras. Plantas Med. 15, 513-519. doi:10.1590/S1516-05722013000400007

Fischer, E., Theisen, I., and Lohmann, L. G. (2004). Bignoniaceae, in The Families and Genera of Vascular Plants ed. K. Kubitzki and J.W. Kadereit (Heidelberg, BW: Springer-Verlag Heidelberg), 9-38. doi:10.1007/978-3-642-18617-2_2

Fonseca-Silva, F., Canto-Cavalheiro, M. M., Menna-Barreto, R. F. S., and AlmeidaAmaral, E. E. (2015). Effect of Apigenin on Leishmania Amazonensis Is Associated with Reactive Oxygen Species Production Followed by Mitochondrial Dysfunction. J. Nat. Prod. 78, 880-884. doi:10.1021/ acs.jnatprod.5b00011

Fotie, J. (2008). The Antiprotozoan Potential of Flavonoids. Pharmacogn. Rev. $2,6-19$.

Grabsk, A. H., Avincola, A. S., Claus, T., Porto, C., Visentainer, J. V., and Pilau, E. J. (2017). Direct Incorporation of Ginger and Oregano Antioxidants in Canola Oil. J. Braz. Chem. Soc. 28, 995-1002. doi:10.21577/0103-5053.20160252

Harborne, J. B. (1967). Comparative Biochemistry of the Flavonoids-VI. Phytochemistry 6, 1643-1651. doi:10.1016/S0031-9422(00)82897-6

$\mathrm{Hu}, \mathrm{C}$, and Kitts, D. D. (2004). Luteolin and Luteolin-7-O-Glucoside from Dandelion Flower Suppress iNOS and COX-2 in RAW264.7 Cells. Mol. Cel. Biochem 265, 107-113. doi:10.1023/b:mcbi.0000044364.73144.fe

Kim, H. K., Cheon, B. S., Kim, Y. H., Kim, S. Y., and Kim, H. P. (1999). Effects of Naturally Occurring Flavonoids on Nitric Oxide Production in the Macrophage Cell Line RAW 264.7 and Their Structure-Activity Relationships. Biochem. Pharmacol. 58, 759-765. doi:10.1016/s0006-2952(99)00160-4

Lima de Medeiros, B. J., Dos Santos Costa, K., Alves Ribeiro, J. F., Carrera Silva, J. O., Ramos Barbosa, W. L., and Tavares Carvalho, J. C. (2011). Liver Protective Activity of a Hydroethanolic Extract of Arrabidaea Chica (Humb. And Bonpl.) B. Verl. (Pariri). Pharmacognosy Res. 3, 79-84. doi:10.4103/0974-8490.81954

Lorenzi, H., and Matos, F. J. (2002). Plantas medicinais no Brasil: nativas e exóticas. Nova Ondessa, SP: Instituto Plantarum, 542.

Mabry, T. J., Markham, K. R., and Thomas, M. B. The Ultraviolet Spectra of Flavones and Flavonols (1970). p. 41-164. doi:10.1007/978-3-642-88458-0_5

Miranda, N., Gerola, A. P., Novello, C. R., Ueda-Nakamura, T., de Oliveira Silva, S., Dias-Filho, B. P., et al. (2017). Pheophorbide a, a Compound Isolated from the Leaves of Arrabidaea Chica, Induces Photodynamic Inactivation of Trypanosoma Cruzi. Photodiagnosis Photodynamic Ther. 19, 256-265. doi:10.1016/j.pdpdt.2017.05.004

Mittra, B., Saha, A., Roy Chowdhury, A., Pal, C., Mandal, S., Mukhopadhyay, S., et al. (2000). Luteolin, an Abundant Dietary Component Is a Potent Antileishmanial Agent that Acts by Inducing Topoisomerase II-Mediated Kinetoplast DNA Cleavage Leading to Apoptosis. Mol. Med. 6, 527-541. doi:10.1007/BF03401792

Mondêgo-Oliveira, R., de Sá Sousa, J. C., Moragas-Tellis, C. J., de Souza, P. V. R., dos Santos Chagas, M. d. S., Behrens, M. D., et al. (2021). Vernonia Brasiliana (L.) Druce Induces Ultrastructural Changes and Apoptosis-like Death of Leishmania Infantum Promastigotes. Biomed. Pharmacother. 133, 111025. doi:10.1016/j.biopha.2020.111025

Moragas-Tellis, C. J., Almeida-Souza, F., Chagas, M. d. S. d. S., Souza, P. V. R. d., Silva-Silva, J. V., Ramos, Y. J., et al. (2020). The Influence of Anthocyanidin
Profile on Antileishmanial Activity of Arrabidaea Chica Morphotypes. Molecules 25, 3547. doi:10.3390/molecules25153547

Mukbel, R. M., Petersen, C., Ghosh, M., Gibson, K., Patten, C., and Jones, D. E. (2007). Macrophage Killing of Leishmania Amazonensis Amastigotes Requires Both Nitric Oxide and Superoxide. Am. J. Trop. Med. Hyg. 76, 669-675. doi:10.4269/ajtmh.2007.76.669

Nijveldt, R. J., van Nood, E., van Hoorn, D. E., Boelens, P. G., van Norren, K., and van Leeuwen, P. A. (2001). Flavonoids: a Review of Probable Mechanisms of Action and Potential Applications. Am. J. Clin. Nutr. 74, 418-425. doi:10.1093/ajcn/74.4.418

Oliveira, I. d. S., Moragas Tellis, C. J., ChagasdS., M. d. S., Behrens, M. D., CalabresedS., K., Abreu-Silva, A. L., et al. (2018). Carapa Guianensis Aublet (Andiroba) Seed Oil: Chemical Composition and Antileishmanial Activity of Limonoid-Rich Fractions. Biomed. Res. Int. 2018, 5032816. doi:10.1155/2018/5032816

Özgen, U., Mavi, A., Terzi, Z., Kazaz, C., Asçi, A., Kaya, Y., et al. (2011). Relationship between Chemical Structure and Antioxidant Activity of Luteolin and its Glycosides Isolated from Thymus Sipyleus Subsp. Sipyleus Var. Sipyleus. Rec. Nat. Prod. 5, 12-21. doi:10.1055/s-0030-1264257

Panche, A. N., Diwan, A. D., and Chandra, S. R. (2016). Flavonoids: an Overview. J. Nutr. Sci. 5, e47. doi:10.1017/jns.2016.41

Paula, J. T., Paviani, L. C., Foglio, M. A., Sousa, I. M. O., and Cabral, F. A. (2013). Extraction of Anthocyanins from Arrabidaea Chica in Fixed Bed Using CO2 and CO2/ethanol/water Mixtures as Solvents. J. Supercrit. Fluids 81, 33-41. doi:10.1016/j.supflu.2013.04.009

Pinheiro, P. F., and Justino, G. C. (2012). "Structural Analysis of Flavonoids and Related Compounds-A Review of Spectroscopic Applications," in Phytochemicals - A Global Perspective of Their Role in Nutrition and Health. Editor Dr. Venketeshwer Rao (London: InTech Europe), 33-56. doi:10.5772/ 29152

Reithinger, R., and Dujardin, J.-C. (2007). Molecular Diagnosis of Leishmaniasis: Current Status and Future Applications. J. Clin. Microbiol. 45, 21-25. doi:10.1128/JCM.02029-06

Rocha, V., Quintino da Rocha, C., Ferreira Queiroz, E., Marcourt, L., Vilegas, W., Grimaldi, G., et al. (2018). Antileishmanial Activity of Dimeric Flavonoids Isolated from Arrabidaea Brachypoda. Molecules 24, 1. doi:10.3390/molecules24010001

Rodrigues, I. A., Azevedo, M., Chaves, F., Alviano, C. S., Alviano, D. S., and Vermelho, A. B. (2014). Arrabidaea Chica Hexanic Extract Induces Mitochondrion Damage and Peptidase Inhibition on Leishmania Spp. Biomed. Res. Int. 2014, 985171. doi:10.1155/2014/985171

Rottini, M. M., Amaral, A. C. F., Ferreira, J. L. P., Oliveira, E. S. C., Silva, J. R. d. A., Taniwaki, N. N., et al. (2019). Endlicheria Bracteolata (Meisn.) Essential Oil as a Weapon against Leishmania Amazonensis: In Vitro Assay. Molecules 24, 2525. doi:10.3390/molecules 24142525

Sampaio, R. d. C. A., da Costa, R. S., de Souza, C. R. F., Júnior, A. P. D., Ribeiro-Costa, R. M., da Costa, C. E. F., et al. (2016). Thermal Characterization of Arrabidaea Chica (Humb. \& Bonpl.) B. Verl. Dry Extracts Obtained by spray Dryer. J. Therm. Anal. Calorim. 123, 2469-2475. doi:10.1007/s10973-015-5123-x

Sen, N., Das, B. B., Ganguly, A., Banerjee, B., Sen, T., and Majumder, H. K. (2006). Leishmania Donovani: Intracellular ATP Level Regulates Apoptosis-like Death in Luteolin Induced Dyskinetoplastid Cells. Exp. Parasitol. 114, 204-214. doi:10.1016/j.exppara.2006.03.013

Silva, M. L. C., Costa, R. S., Santana, A. D. S., and Koblitz, M. G. B. (2010). Compostos fenólicos, carotenóides e atividade antioxidante em produtos vegetais. Sem. Ci. Agr. 31, 669-681. doi:10.5433/1679-0359.2010v31n3p669

Singh, M., Kaur, M., and Silakari, O. (2014). Flavones: an Important Scaffold for Medicinal Chemistry. Eur. J. Med. Chem. 84, 206-239. doi:10.1016/ j.ejmech.2014.07.013

Siraichi, J. T. G., Felipe, D. F., Brambilla, L. Z. S., Gatto, M. J., Terra, V. A., Cecchini, A. L., et al. (2013). Antioxidant Capacity of the Leaf Extract Obtained from Arrabidaea Chica Cultivated in Southern Brazil. PLoS One 8, e72733. doi:10.1371/journal.pone. 0072733

Sundar, S., Chakravarty, J., and Meena, L. P. (2019). Leishmaniasis: Treatment, Drug Resistance and Emerging Therapies. Expert Opin. Orphan Drugs 7, 1-10. doi:10.1080/21678707.2019.1552853

Takemura, O., Iinuma, M., Tosa, H., Miguel, O. G., Moreira, E. A., and Nozawa, Y. (1995). A Flavone from Leaves of Arrabidaea Chica F. Cuprea. Phytochemistry 38, 1299-1300. doi:10.1016/0031-9422(94)00786-S

Tasdemir, D., Kaiser, M., Brun, R., Yardley, V., Schmidt, T. J., Tosun, F., et al. (2006). Antitrypanosomal and Antileishmanial Activities of Flavonoids and 
Their Analogues: In Vitro, In Vivo, Structure-Activity Relationship, and Quantitative Structure-Activity Relationship Studies. Antimicrob. Agents Chemother. 50, 1352-1364. doi:10.1128/AAC.50.4.1352-1364.2006

Vaca, E., Behrens, C., Theccanat, T., Choe, J.-Y., and Dean, J. V. (2017). Mechanistic Differences in the Uptake of Salicylic Acid Glucose Conjugates by Vacuolar Membrane-Enriched Vesicles Isolated fromArabidopsis Thaliana. Physiol. Plantarum 161, 322-338. doi:10.1111/ppl.12602

Vasconcelos, C. C., Lopes, A. J. O., Sousa, E. L. F., Camelo, D. S., Lima, F. C. V. M., Rocha, C. Q. d., et al. (2019). Effects of Extract of Arrabidaea Chica Verlot on an Experimental Model of Osteoarthritis. Ijms 20, 4717. doi:10.3390/ ijms20194717

Wong, I. L. K., Chan, K.-F., Chan, T. H., and Chow, L. M. C. (2012). Flavonoid Dimers as Novel, Potent Antileishmanial Agents. J. Med. Chem. 55, 8891-8902. doi:10.1021/jm301172v

World Health Organization (2020). Leishmaniasis. Available at: https://www.who. int/health-topics/leishmaniasis\#tab=tab_1 (Accessed August 07, 2020).
Zorn, B., García-Piñeres, A. J., Castro, V., Murillo, R., Mora, G., and Merfort, I. (2001). 3-Desoxyanthocyanidins from Arrabidaea Chica. Phytochemistry 56, 831-835. doi:10.1016/s0031-9422(01)00038-3

Conflict of Interest: The authors declare that the research was conducted in the absence of any commercial or financial relationships that could be construed as a potential conflict of interest.

Copyright (ㄷ) 2021 Silva-Silva, Moragas-Tellis, Chagas, Souza, Souza, Hardoim, Taniwaki, Moreira, Dutra Behrens, Calabrese and Almeida-Souza. This is an openaccess article distributed under the terms of the Creative Commons Attribution License (CC BY). The use, distribution or reproduction in other forums is permitted, provided the original author(s) and the copyright owner(s) are credited and that the original publication in this journal is cited, in accordance with accepted academic practice. No use, distribution or reproduction is permitted which does not comply with these terms. 